\title{
EL DERECHO DE LOS PARLAMENTARIOS A RECABAR DOCUMENTACIÓN ADMINISTRATIVA. NUEVAS PERSPECTIVAS JURISPRUDENCIALES A RAÍZZ DE SU CRECIENTE JUDICIALIZACIÓN
}

IGNACIO DURBÁN MARTÍN 
SUMARIO

1. INTRODUCCIÓN. 2. LA INTERPRETACIÓN JURISPRUDENCIAL DE ESTE DERECHO: RECIENTES APLICACIONES (Y MODULACIONES) POR PARTE DE LA JURISDICCIÓN CONTENCIOSO-ADMINISTRATIVA DE CRITERIOS DOCTRINALES CONSOLIDADOS EN LA JURISPRUDENCIA DEL TRIBUNAL CONSTITUCIONAL. 2.1. Tipología y elementos definitorios del derecho. a) Una manifestación del derecho fundamental del artículo 23.2 CE. b) Un derecho que responde a la función de control al Gobierno. c) Un derecho extensible al ámbito autonómico y local. d) Un derecho de configuración legal. e) Un derecho reforzado por la legislación de transparencia y por la jurisprudencia del TJUE. f) ¿Un derecho ilimitado? 2.2. Situaciones potencialmente conflictivas derivadas del ejercicio de este derecho. a) ¿Qué pasa cuando la documentación que se solicita se halla afectada por un secreto sumarial? b) ¿Qué pasa cuando la documentación que se solicita es un informe o documento de trabajo concebido para la exclusiva circulación interna en la administración? c) ¿Qué pasa cuando la documentación que se solicita no existe físicamente? d) ¿Qué pasa cuando la documentación que se solicita está afectada por la protección de datos de carácter personal? e) ¿Qué pasa cuando la documentación que se solicita involucra «cláusulas de confidencialidad» de un contrato público? f) ¿Qué pasa cuando la documentación que se solicita está en fase de elaboración, es decir, se trata de informes o procedimientos en curso? g) ¿Qué pasa cuando la documentación que se solicita es ingente ( $\mathrm{y}$ a menudo con localización dispersa)? h) ¿Qué pasa cuando la documentación que se solicita es muy genérica? i) ¿Qué pasa cuando la documentación que se solicita implica a otras administraciones que gozan de autonomía propia? 3. SU GARANTÍA JURISDICCIONAL. 3.1. Pluralidad de vías para la satisfacción de este derecho. 3.2. Referencia a una polémica procesal de calado: ¿compete o no a la jurisdicción contencioso-administrativa enjuiciar actos del Gobierno que deniegan información a un representante político? 3.3. Consideraciones adicionales sobre la «efectividad» y la «idoneidad» de la garantía jurisdiccional de este derecho. 4. UN APUNTE FINAL SOBRE EL (POTENCIAL) EJERCICIO ABUSIVO DE ESTE DERECHO. 5. ANEXO JURISPRUDENCIAL. 


\title{
EL DERECHO DE LOS \\ PARLAMENTARIOS A RECABAR DOCUMENTACIÓN ADMINISTRATIVA. NUEVAS PERSPECTIVAS JURISPRUDENCIALES A RAÍZ DE SU CRECIENTE JUDICIALIZACIÓN
}

\author{
IGNACIO DURBÁN MARTÍN ${ }^{1}$ \\ Universitat de València
}

The proper office of a representative assembly is to watch and control the government: to throw the light of publicity on its acts; to compel a full exposition and justification of all of them which any one considers questionable; to censure them if found condemnable, and, if the men who compose the government abuse their trust, or fulfill it in a manner which conflicts with the deliberate sense of the nation, to expel them from office, and either expressly or virtually appoint their successors.

John Stuart Mill, Considerations on Representative

Government, 1861

\section{INTRODUCCIÓN}

Tanto la configuración normativa como la interpretación jurisprudencial del derecho de los parlamentarios a recabar documentación de las administraciones públi-

${ }^{1}$ Departamento de Derecho Constitucional y Ciencia Política y de la Administración (Facultad de Derecho - Universidad de Valencia). Avda.dels Tarongers, s/n. 46022 Valencia (España). Email: Ignacio.Durban@uv.es 
cas han sido objeto de numerosos estudios y comentarios a lo largo de las últimas décadas debido a la capital importancia que tiene este derecho en el marco de nuestro sistema representativo multinivel ${ }^{2}$. Y es que, no cabe duda de que, tal y como puso de manifiesto Javier García Roca hace ya casi dos décadas, «la posesión de una adecuada y singularizada información por los miembros de las Cámaras es imprescindible para el correcto ejercicio de todas las funciones parlamentarias y, en especial, porque las solicitudes individuales de información son uno de los principales medios que permiten al representante ejercer una continuada discusión pública de la acción del Gobierno»³.

Pues bien, a la vista del cúmulo de novedades relevantes acaecidas durante los últimos años en el ámbito jurisprudencial, se ha hecho necesario volver sobre el estudio de esta materia. En concreto, el foco de los cambios acontecidos durante la última década en torno a esta cuestión se sitúa en la Comunitat Valenciana, que es el lugar donde, en el marco de la VII legislatura (y ulteriores) de Les Corts, comenzó —y, por vez primera en nuestra historia democrática, halló continuidad procesal— la judicialización en la vía contencioso-administrativa de este derecho que asiste a los representantes políticos. Dicha conflictividad ha dado lugar, con los años, a un elevado número de resoluciones tanto del Tribunal Superior de Justicia de la Comunitat Valenciana (TSJCV) como del Tribunal Supremo (TS). Un total de más de cuarenta sentencias - todas ellas recogidas de forma cronológica en el anexo final de este artículo- que, como no podía ser de otra manera, han incidido de forma reseñable en la delimitación de los contornos de este derecho. En lo que sigue se examinarán todas estas sentencias vinculando los puntos coincidentes que presentan sus argumentaciones a fin de poder ofrecer un análisis de los principales criterios jurisprudenciales empleados en ellas que, necesariamente, deberán ser examinados en paralelo a la

\footnotetext{
${ }^{2}$ Sin perjuicio de que a lo largo de las siguientes páginas vaya haciéndose referencia a diversa bibliografía sobre el particular (priorizando la de los últimos años) parece oportuno incluir una relación inicial de algunas de las contribuciones clásicas en esta materia. Así, siguiendo un orden cronológico, cabe remitirse aquí a las siguientes: Silva Ochoa, J. C. (1990). «El derecho de los parlamentarios a la documentación». Revista de las Cortes Generales, n. ${ }^{\circ}$ 19, pp. 7-41; las contribuciones de Aragón Reyes, M., Peñaranda Ramos J. L. y Sáinz Moreno, F., todas ellas incluidas en VV. AA. (1994). Instrumentos de información de las cámaras parlamentarias, Madrid, CEC; Embid Irujo, A. (1996). «El derecho a la información del Parlamento y de los parlamentarios. Nuevas reflexiones a la luz de las innovaciones del ordenamiento jurídico». Anuario Jurídico de La Rioja, n. ${ }^{2}$ 2, pp. 289-320; Cano Bueso, J. (1996). El «derecho de acceso a la documentación» de los diputados en el ordenamiento parlamentario español, Madrid, Congreso de los Diputados; Mancisidor Artaraz, E. (1997). «El derecho de información de los parlamentarios en la jurisprudencia constitucional», en Pau i Vall, F. (coord.), Parlamento y Justicia Constitucional. IV Jornadas de la Asociación Española de Letrados de Parlamentos, Pamplona, Aranzadi, pp. 323-364; Martínez Elipe, L. (2002). Tratado de Derecho Parlamentario. Vol. II. Parlamento e información, Pamplona, Aranzadi; Arruego Rodríguez, G. (2003). «Sobre el ‘derecho a la documentación’ de los parlamentarios en la jurisprudencia constitucional». Revista Española de Derecho Constitucional, n. ${ }^{\circ}$ 68, pp. 335-378.

3 García Roca, J. (1999). Cargos públicos representativos. Un estudio del artículo 23.2 de la Constitución, Pamplona, Aranzadi, pp. 303-304.
} 
específica jurisprudencia que ha venido dictando el Tribunal Constitucional (TC) hasta la fecha sobre esta misma cuestión.

\section{LA INTERPRETACIÓN JURISPRUDENCIAL DE ESTE DERECHO: RECIENTES APLICACIONES (Y MODULACIONES) POR PARTE DE LA JURISDICCIÓN CONTENCIOSO-ADMINISTRATIVA DE CRITERIOS DOCTRINALES CONSOLIDADOS EN LA JURISPRUDENCIA DEL TRIBUNAL CONSTITUCIONAL}

La casuística judicial asociada a las relaciones gobierno-parlamento en el ámbito de la Comunitat Valenciana ha propiciado la adopción de una serie de criterios jurisprudenciales esclarecedores en torno al derecho individual de los representantes políticos a recabar documentación de las administraciones públicas. Un derecho que, no está de más precisarlo, es distinto del derecho que asiste a las comisiones parlamentarias a obtener información; $y$, puesto que la citada jurisprudencia únicamente se ha ocupado de la dimensión individual del derecho, es sólo a ésta a la que se prestará atención a lo largo del presente trabajo.

Desde un inicio conviene clarificar que ni el TSJCV ni el TS han elaborado categorías interpretativas propias a este respecto que puedan calificarse de innovadoras puesto que, en realidad, ambos tribunales se han limitado a aplicar (modulándola convenientemente según los supuestos) la doctrina sobre el ius in officium de los representantes políticos que el TC ha ido erigiendo durante las décadas anteriores en el marco de supuestos de hecho similares — si bien, cabe remarcarlo, prácticamente nunca ubicados en la tesitura específica de las controversias entre los poderes ejecutivo y legislativo - . Con todo, sí puede decirse que la jurisdicción contencioso-administrativa, al haberse enfrentado a una ingente casuística en los últimos años, ha desempeñado una labor relevante en la medida en que sus sentencias han contribuido a trasladar y a adecuar, con notable esfuerzo racionalizador, las categorías generales presentes en la jurisprudencia constitucional al específico supuesto - escasamente conflictivo hasta hace pocos años — del derecho de los parlamentarios a recabar documentación administrativa.

De este modo, puede decirse que, por su parte, la jurisprudencia constitucional ha ido depurando una serie de criterios que han permitido delimitar con cierta claridad los márgenes de este derecho, es decir, sus perfiles internos y sus límites externos, corroborando a qué tipología pertenece y precisando cuáles son sus principales elementos definitorios. Y, por otro lado, la jurisprudencia de los tribunales contencioso-administrativos, tomando como punto de partida dichos parámetros, ha coadyuvado en los últimos años a asentar algunos de los criterios fijados con anterioridad, al tiempo que ha desarrollado otros e, incluso, ha complementado la doctrina general con ciertos planteamientos adicionales. Así pues, queda claro que el juego combinado de ambas jurisprudencias — la constitucional y la contencioso-administrativa- ha 
ido conformando un acervo interpretativo de notable envergadura que tiene interés examinar a fin de valorar en qué punto nos encontramos con relación a este derecho de los representantes políticos. Y ésta es, precisamente, la tarea que corresponde realizar en las páginas que siguen.

\subsection{Tipología y elementos definitorios del derecho}

a) Una manifestación del derecho fundamental del artículo $23.2 \mathrm{CE}$

La jurisprudencia proveniente de los tribunales contencioso-administrativos dictada en los últimos años ha puesto de manifiesto —en aplicación de un criterio plenamente consolidado en la doctrina del TC - que nos hallamos ante un derecho fundamental ${ }^{4}$. En concreto, se ha reiterado la idea asentada de que el derecho de los parlamentarios a recabar documentación administrativa se inserta dentro del derecho más amplio proclamado en el art. 23.2 CE («derecho a acceder en condiciones de igualdad a las funciones y cargos públicos») $)^{5}$ habida cuenta de que, como es sabido, la jurisprudencia constitucional atribuyó desde muy temprano a este derecho fundamental (además de una doble vertiente referida tanto al empleo público como a la

${ }^{4}$ Una (contundente) opinión que cuestiona, no sólo la conceptuación de las peticiones de documentación administrativa como manifestación de un derecho fundamental de los parlamentarios, sino la misma constitucionalidad de este instrumento de control al Gobierno, en Santaolalla López, F. (2013). «Información parlamentaria, derechos de los diputados y control jurisdiccional». Revista de las Cortes Generales, n. ${ }^{\circ} 89$, pp. 89-133. Esta posición ha sido, a su vez, recientemente criticada con fundamento en sólidos argumentos — que comparto— en Lucas Murillo de la Cueva, P. (2016). «La garantía jurisdiccional del derecho de los parlamentarios a la documentación administrativa», en VV. AA., La última jurisprudencia relativa al Parlamento, Vitoria-Gasteiz, Parlamento Vasco, pp. 155-196.

${ }^{5}$ El TC ha rechazado expresamente el posible encaje de esta facultad de los parlamentarios tanto en el ámbito del derecho de petición (ex art. 29.1 CE) como en el del derecho a recibir información veraz (ex art. 20.1 d) CE). Sobre el derecho de petición, el Alto Tribunal ha argumentado que «el derecho de petición del art. 29.1 de la Constitución no protege pretensiones que se deduzcan con base a reglas singulares ordenadoras de las funciones y facultades que correspondan a quienes ostenten el status específico de miembros de órganos colegiados»; agregando, en referencia al concreto supuesto enjuiciado, que «los demandantes no han ejercitado un derecho de petición en su condición genérica de ciudadanos españoles, sino que han hecho uso, en su calidad de Diputados de las Cortes de Castilla-La Mancha, de la facultad de recabar información que les confiere el art. 12.2 del Reglamento de dichas Cortes» (STC 161/1988, FJ 5). También, a este respecto, el TC ha dicho que el derecho de petición «se formula en relación con los ciudadanos en cuanto tales, no en relación, con quienes ya participan en representación de sus conciudadanos mediante el ejercicio de su función parlamentaria» (ATC 426/1990, FJ 4). En cuanto al derecho a recibir información veraz, el TC ha considerado que «es éste un derecho que tiene como características esenciales estar dirigido a los ciudadanos en general al objeto de que puedan formar sus convicciones, ponderando opiniones divergentes e incluso contradictorias y participar así en la discusión relativa a los asuntos públicos; es decir, se trata de un derecho que nada tiene que ver con los controles políticos que las Leyes atribuyan a las Asambleas Legislativas y a sus miembros sobre la acción de gobierno, en el seno de sus relaciones institucionales con el Poder Ejecutivo» (STC 220/1991, FJ 4). 
representación) una triple dimensión: acceso, permanencia y ejercicio del cargo $^{6}$. Y esta última faceta es, precisamente, la que despliega sus efectos en el caso que aquí nos ocupa. Se trata de lo que el propio TC ha denominado un ius in officium, es decir, un conjunto de facultades que identifican la labor del representante y, entre las cuales, debe incluirse la de recabar documentación de las administraciones públicas.

Así pues, desde la primera de las controversias suscitadas por este motivo en el ámbito autonómico valenciano ante los tribunales contencioso-administrativos cuya doctrina es la que interesa analizar aquí-, tanto el TSJCV (véase la STSJCV, 5. ${ }^{\mathrm{a}}$, de 29 de abril de 2011, recurso 659/2009, FD 3) como posteriormente el TS (véase la STS, Sala de lo Contencioso, Sección 7. a, de 25 de febrero de 2013, recurso 4268/2011, FD 6), constataron (en aplicación de los criterios de alcance más general establecidos con anterioridad en la jurisprudencia constitucional) el vínculo existente entre el derecho de los parlamentarios a recabar documentación administrativa y el art. 23.2 CE.

Más específicamente, la doctrina del TC que ha fijado el marco interpretativo en materia de acceso de los parlamentarios a la información como derecho fundamental, es la contenida en las SSTC $161 / 1988^{7}, 181 / 1989^{8}, 220 / 1991^{9}, 203 / 2001^{10}, 57 / 2011^{11}$ y

${ }^{6}$ Véanse, en este sentido, las SSTC 5/1983, FJ 3; 10/1983, FJ 2; 28/1984, FJ 2; 32/1985, FJ 3; 161/1988, FFJJ 6 y 7; 181/1989, FJ 4; 205/1990, FJ 5; 220/1991, FJ 5; 225/1992, FJ 1; 38/1999, FJ 2; 27/2000, FJ 4; 177/2002, FJ 3; 40/2003, FJ 2; 208/2003, FJ 4; 227/2004, FJ 2; 89/2005, FJ 2; 90/2005, FJ 2; 141/2007, FJ 3; 298/2006, FJ 6; 361/2006, FJ 2; 74/2009, FJ 2; 190/2009, FJ 2; 88/2012, FJ 2; 246/2012, FJ 4; 200/2014, FJ 4; 201/2014, FJ 3; 202/2014, FJ 3; 1/2015, FJ 3; 107/2016, FJ 4; 108/2016, FJ 4; 199/2016, FJ 3; 212/2016, FJ 3; 224/2016, FJ 2; 225/2016, FJ 2; 11/2017, FJ 3; 32/2017, FJ 3; 76/2017, FJ 3; 4/2018, FJ 3; 10/2018, FJ 3; así como los AATC $181 / 2003$, FJ 2; 200/2004, FJ 3; y 85/2006, FJ 6.

7 Trae causa de un recurso de amparo planteado por un grupo de parlamentarios contra un acto de la Mesa de las Cortes de Castilla-La Mancha, por el cual se decidió no admitir a trámite cuatro solicitudes de documentación al Consejo de Gobierno de la Junta de Comunidades de Castilla-La Mancha, sobre la cuantía, empleo y destino de determinadas ayudas y subvenciones dispensadas por la administración autonómica en el ámbito de la producción y de la comercialización agrarias.

8 Trae causa de un recurso de amparo interpuesto por un grupo de parlamentarios contra el acuerdo de la Mesa del Parlament de Cataluña en virtud del cual se interpretaba el Reglamento de dicha Cámara de manera tal que se impedía que un diputado pudiese acceder a determinada información administrativa en compañía de asesores técnicos especialistas.

9 Trae causa de un recurso de amparo formulado por nueve miembros del Parlamento Vasco, componentes del Grupo Parlamentario de Euskadiko Ezquerra, contra la contestación que dio el Gobierno vasco a la solicitud de información sobre el destino de determinados gastos, habilitados como «reservados» en los Presupuestos de los años 1988 y 1989, solicitada por dos de dichos parlamentarios.

10 Trae causa de una serie de recursos de amparo acumulados contra los acuerdos de la Mesa del Congreso de los Diputados de inadmisión a trámite de solicitud de informe a la Administración General del Estado sobre diversos expedientes por infracción fiscal, por considerar que los datos solicitados se encontraban comprendidos en el ámbito de reserva acotado por el art. 113.1 de la Ley General Tributaria.

11 Trae causa de un recurso de amparo interpuesto por un diputado contra un acuerdo de la Mesa del Congreso de los Diputados que inadmitía a trámite una solicitud de información dirigida a la Confederación Hidrográfica del Guadalquivir por no contar con la firma del portavoz del grupo parlamentario. 
32/2017 $7^{12}$; así como el ATC 426/1990 ${ }^{13}$. Estas resoluciones son las que han establecido una serie de criterios de interés a este respecto. En síntesis, las citadas resoluciones contienen las siguientes ideas principales:

- Que el derecho a la información es un «derecho individual a recabar, en la forma y con los requisitos que el mismo Reglamento establece, información [en ese caso] a la Administración Regional, el cual por venir integrado en el status propio del cargo de diputado se inserta y forma parte del derecho fundamental que garantiza el artículo 23.2 de la Constitución» (STC 161/1988, FJ 7).

- Que este derecho de los parlamentarios reúne las características de un ius ut procedatur, en la medida en que obliga a los órganos de las asambleas legislativas a dar curso a la solicitud de información, pues dichos órganos internos carecen de la facultad de efectuar un «control de oportunidad sobre la conveniencia o inconveniencia de hacer llegar a la Administración (...) la solicitud de información que aquéllos formulen» (STC 161/1988, FJ 8), así como tampoco poseen la capacidad de realizar «un examen del contenido material de la iniciativa», debiendo dar curso a esas peticiones de información, siempre que «no se aprecien carencias o deficiencias relevantes en su presentación o en su redacción» (STC 203/2001, FJ 5). Con todo, según ha indicado el propio TC, esta construcción admite posibles matices (ninguno de los cuales se halla, a mi juicio, satisfactoriamente perfilado todavía $\left.{ }^{14}\right)$.

12 Trae causa de un recurso de amparo promovido por el Grupo Parlamentario Popular de las Cortes de Castilla-La Mancha contra un acuerdo de su Mesa en virtud del cual se inadmitieron a trámite determinadas solicitudes de información dirigidas al gobierno autonómico por concernir a asuntos anteriores a los últimos cuatro años (límite temporal establecido según un uso parlamentario consolidado en esa asamblea legislativa).

13 Trae causa de un recurso de amparo interpuesto por un grupo de diputados del Partido Popular de las Cortes de Castilla-La Mancha, que, tras solicitar un informe al gobierno autonómico (relativo a una sociedad pública), recibieron una respuesta que consideraron «en la práctica una negativa a proporcionar la información solicitada».

${ }^{14}$ La STC 161/1988 ya contempla como hipótesis que «la Mesa rechace escritos en los que se planteen cuestiones entera y manifiestamente ajenas a las atribuciones de la Cámara» (FJ 8). En la STC 203/2001 (con cita de jurisprudencia anterior sobre potestad de las Mesas en materia de calificación y admisión a trámite de escritos y documentos) se habla de la posibilidad de que la Mesa, más allá de la estricta verificación de los requisitos formales de la solicitud, pueda ejercer un control material sobre la legalidad aplicable a la misma, incluyendo mención de la Constitución, el bloque de la constitucionalidad y el reglamento parlamentario (FJ 3). La STC 57/2011 recoge expresamente todas las ideas anteriormente apuntadas (FJ 3). Y, por su parte, la STC 32/2017 afirma que la Mesa puede fundamentar su decisión de calificación y admisión a trámite «en la existencia de una conexión o no de los documentos requeridos con dicha función de control» (FJ 6 in fine). En cualquier caso, y al margen de todo ello, el TC siempre ha insistido en que «la decisión sobre la admisión de dicha clase de peticiones no podrá en ningún caso desconocer que son manifestación del ejercicio de un derecho del parlamentario que las formula y que, por ello, cualquier rechazo arbitrario o no motivado causará lesión de dicho derecho» (STC 161/1988, FJ 8). Es lo que las SSTC 57/2011 (FJ 7) y 32/2017 (FJ 6) han llamado una motivación «materialmente respetuosa con el art. 23.2». 
- Que este derecho implica que la información solicitada debe ser obtenida. En concreto, a este respecto, ha dicho el TC que: «el derecho ex art. 23.2 CE comprende tanto el de solicitar una determinada información de las Administraciones públicas como el de obtenerla de éstas. Lo que determina que su ejercicio se encuadre en las relaciones institucionales «entre Ejecutivo y Legislativo» y, consiguientemente, que este derecho pueda ser lesionado «bien por el Ejecutivo, bien por los propios órganos de las Cámaras» (STC 196/1990, de 29 de noviembre, FJ 7)» (STC 203/2001, FJ 3).

-Que, sin perjuicio de lo señalado en el anterior punto, «la denegación o incompleta satisfacción de una pregunta o petición de información formuladas por parlamentarios no supone, por sí misma, la vulneración del derecho fundamental al ejercicio del cargo garantizado por el art. 23 C.E.» (ATC 426/1990, FJ 3), puesto que este derecho «no comprende el derecho a una respuesta con un concreto contenido» (STC 220/1991, FJ 5).

Pues bien, tal y como se ha dicho anteriormente, todas las resoluciones de la jurisdicción contencioso-administrativa posteriores a las dos antes citadas — la del TSJCV, 29 de abril de 2011, y la del TS, de 25 de febrero de 2013 - no han hecho sino reiterar — y desarrollar — tales criterios, con la señalada excepción del último de los apuntados, esto es, el que determina que la satisfacción incompleta o incluso la denegación de la información no comporta per se la vulneración del derecho fundamental. Y es que, como habrá ocasión de examinar más adelante, la jurisprudencia contencioso-administrativa de los últimos años se ha decantado en casi todos los supuestos por entender que la satisfacción incompleta o la denegación de información implica (casi) automáticamente la vulneración del derecho fundamental del art. 23.2 CE. Una acusada inercia cuya compatibilidad con la exigencia contenida en el artículo 5.1 de la Ley Orgánica del Poder Judicial (según la cual todos los jueces y tribunales, incluido el Tribunal Supremo, deben ajustar sus pronunciamientos a los dictados por el Tribunal Constitucional) plantea no pocas dudas.

Asimismo, en torno a la cuestión de la jurisprudencia constitucional invocada desde los tribunales contencioso-administrativos durante estos últimos años, no puede dejar de mencionarse un hecho que resulta (hasta cierto punto) llamativo. Y es que, existiendo como existen resoluciones dictadas por el TC expresamente referidas al derecho de los parlamentarios a recabar documentación de las administraciones públicas — que son, en concreto, las siete señaladas supra—, sorprende que, tanto el TSJCV como el TS, hayan preferido invocar en sus resoluciones otros fallos del TC no específicamente concernientes a este derecho, sino a otros distintos (aunque igualmente subsumibles dentro del ius in officium del que son titulares los parlamentarios). En este sentido, la STC 190/2009, ha sido, con amplia diferencia, la más citada (operando en la práctica como el leading case en la materia), pese a que se trata de un pronunciamiento sobre un supuesto de denegación de una comparecencia - y no de documentación — por la propia Mesa del Congreso de los Diputados — y no por parte del 
Gobierno- Siguiendo esta misma pauta, en los últimos tiempos, se han invocado otras resoluciones del TC — como es el caso de las SSTC 44/2010, 88/2012, $107 / 2016$, 108/2016 y 225/2016 — que tampoco se ajustan con precisión al presupuesto de hecho enjuiciado, es decir, al derecho de los parlamentarios a recabar documentación administrativa. Al respecto, cabe pensar, que los citados tribunales contencioso-administrativos han primado, en este punto, la referencia a precedentes jurisprudenciales más recientes, en detrimento de su exacta adecuación a los específicos supuestos enjuiciados; cuestión esta última que, por lo demás, no reviste problema alguno ya que la aplicación analógica de esta doctrina del TC parece sobradamente justificada por tener como denominador común la interpretación del ius in officium.

Por otra parte, no debe desatenderse que la jurisprudencia constitucional subrayó también desde muy temprano —y esta es una idea que también ha sido invocada por la jurisprudencia del TSJCV y del TS estos últimos tiempos- la existencia de una lógica de vasos comunicantes entre el art. 23.2 y el 23.1 CE, llegándose a afirmar que «la norma contenida en el art. 23.1 resulta inseparable de la del art. 23.2» (STC 161/1988, FJ 6) o que «los dos párrafos del art. 23 son inseparables» (STC 225/1992, FJ 1). La argumentación que ofrece el TC es la que se transcribe a continuación:

En una línea jurisprudencial que se inicia con las SSTC 5/1983, de 4 de febrero, y 10/1983, de 21 de febrero, este Tribunal ha establecido una directa conexión entre el derecho de un parlamentario ex art. 23.2 CE y el que la Constitución atribuye a los ciudadanos a participar en los asuntos públicos (art. 23.1 CE), pues «puede decirse que son primordialmente los representantes políticos de los ciudadanos quienes dan efectividad a su derecho a participar en los asuntos públicos. De suerte que el derecho del art. 23.2, así como, indirectamente, el que el art. 23.1 CE reconoce a los ciudadanos, quedaría vacío de contenido, o sería ineficaz, si el representante político se viese privado del mismo o perturbado en su ejercicio» [SSTC 38/1999, de 22 de marzo, FJ 2; 107/2001, de 23 de abril, FJ 3 a); 203/2001, de 15 de octubre, FJ 2; 177/2002, de 14 de octubre, FJ 3]. (ATC 181/2003, FJ 2) ${ }^{15}$

Este vínculo inescindible entre ambos apartados del precepto adquiere particular relevancia cuando se dirimen controversias como las relativas al derecho de información de los parlamentarios por cuanto dicha interconexión confiere al citado derecho una posición notablemente reforzada y merecedora de especial protección y tutela por parte de los tribunales en la medida en que entronca directamente con el principio democrático.

15 Otras resoluciones del TC en las que se deja constancia de la conexión que existe entre los dos apartados que integran el artículo 23 CE son las siguientes: SSTC 28/1984, FJ 2; 38/1999, FJ 2; 27/2000, FJ 4; 40/2003, FJ 2; 227/2004, FJ 2; 89/2005, FJ 2; 90/2005, FJ 2; 361/2006, FJ 2; 44/2010, FJ 3; 57/2011, FJ 2; 88/2012, FJ 2; 200/2014, FJ 4; 202/2014, FJ 3; 199/2016, FJ 3; 212/2016, FJ 3; 224/2016, FJ 2; 225/2016, FJ 2; 11/2017, FJ 3; 32/2017, FJ 3; 76/2017, FJ 3; y 10/2018, FJ 3. 
También debe tenerse presente — si bien se trata de una cuestión sobre la que más adelante se incidirá- que este derecho de los parlamentarios, más allá de emanar del art. 23.2 CE, tiene una relación directa con otros dos artículos de la Constitución: el 109 (según el cual: «Las Cámaras y sus Comisiones podrán recabar, a través de los Presidentes de aquéllas, la información y ayuda que precisen del Gobierno y de sus Departamentos y de cualesquiera autoridades del Estado y de las Comunidades Autónomas») y el 66.2 (en lo relativo a la función de control al Gobierno que corresponde a las Cortes Generales). Así lo ha subrayado toda la jurisprudencia, teniendo particular importancia a este respecto los pronunciamientos tanto del TC (véase la STC 203/2001, FJ 3) como del TS (véase nuevamente la STS, Sala de lo Contencioso, Sección 7. a, de 25 de febrero de 2013, recurso $4268 / 2011$, FD 6).

b) Un derecho que responde a la función de control al Gobierno

El derecho a la información y a la documentación que asiste a los representantes políticos resulta, sin duda, necesario como instrumento para el ejercicio de la función de control del Gobierno, función nuclear en el parlamento y sin cuya existencia no sería posible afirmar la existencia de Constitución ${ }^{16}$. Así lo ha entendido la jurisprudencia del TC cuando ha afirmado que esta manifestación específica del ius in officium constituye:

un aspecto particular de la función de control genéricamente atribuida a las Cortes Generales en el art. 66.2 CE. Y su finalidad específica es la de conocer determinados hechos y situaciones, así como los documentos administrativos que los evidencian, relativos a la actividad de las Administraciones públicas; información que bien puede agotar sus efectos en su obtención o ser instrumental y servir posteriormente para que el Diputado que la recaba, o su Grupo parlamentario, lleven a cabo un juicio o valoración sobre esa concreta actividad y la política del Gobierno, utilizando otros instrumentos de control. (STC 203/2001, FJ 3)

La jurisprudencia contencioso-administrativa también se ha manifestado en este sentido. En concreto, el TSJCV ha dicho expresamente que «el fundamento de la información solicitada» en el marco de este tipo de casos es esencialmente «el control parlamentario del Gobierno» (véase, entre otras, la primera de las resoluciones dictadas por el citado tribunal sobre esta materia, es decir, la STSJCV, 5. ${ }^{a}$, de 29 de abril de 2011, recurso 659/2009, FD 3). Y, por su parte, el TS también ha reiterado esta misma idea cuando ha dicho que el derecho a obtener información de los parlamentarios «sirve al ejercicio de las funciones que les son propias y, entre ellas, ciertamente, pero no sólo, a la de controlar la acción política del Gobierno»; o cuando ha expresado que «nos encontramos, pues, con una relación jurídica de derecho-deber en

16 Aragón Reyes, M. (2002). Constitución, Democracia y Control, México, UNAM, p. 190. 
la que la posición activa de los parlamentarios se corresponde con la pasiva del Gobierno» (STS, Sala de lo Contencioso, Sección 7. a, de 25 de febrero de 2013, recurso 4268/2011, FD 6).

c) Un derecho extensible al ámbito autonómico y local

Desde los inicios del actual período democrático se entendió que el derecho de los representantes políticos a recabar documentación administrativa no pertenecía en exclusiva a los integrantes de las Cortes Generales, sino que era también extensible a los diputados de las asambleas legislativas autonómicas y a los miembros de las entidades locales ${ }^{17}$. El TC se ha manifestado con rotundidad en tal sentido: sobre los diputados de las asambleas legislativas autonómicas, desde la STC 161/1988; sobre los concejales, desde la STC 5/1983; y sobre los diputados provinciales, desde la STC 163/1991. Por su parte, la jurisprudencia contencioso-administrativa del TSJCV y del TS examinada supra, no ha hecho sino constatar esta pacífica y unánimemente aceptada cuestión.

Esta extensión del derecho a los subsiguientes niveles territoriales de poder cuenta también con un sólido respaldo normativo. Por lo que respecta a las asambleas legislativas autonómicas, además de los correspondientes reglamentos parlamentarios, se hallan — junto a otras leyes a las que después se hará referencia- los Estatutos de Autonomía, que al ser las normas que regulan el marco de las relaciones gobierno-parlamento en el ámbito autonómico respectivo, suelen contener previsiones de interés a efectos de lo que aquí se estudia. No en vano, prácticamente toda la jurisprudencia contencioso-administrativa surgida a raíz de la conflictividad suscitada en la Comunitat Valenciana durante los últimos años, ha hecho hincapié en que el art. 22 del Estatuto de Autonomía de 2006 establece que son funciones de Les Corts todas aquellas que las leyes les atribuyan ${ }^{18}$; precepto que los tribunales ponen en conexión directa con el contenido del reglamento de la asamblea legislativa en cuanto al derecho a recabar información que asiste a sus miembros. No obstante, en este punto, también podría subrayarse — y resulta llamativo que la jurisprudencia no lo haya hecho- que el propio art. 22 del Estatuto de Autonomía hace referencia expresa tanto a la función parlamentaria de «controlar la acción del Consell» (apartado «b») como a la de «ejercer el control parlamentario sobre la acción de la administración situada bajo la autoridad de la Generalitat» (apartado «e»). En cuanto al nivel local resulta aquí de aplicación la Ley 7/1985, de

17 Por lo que respecta a los miembros de las entidades locales, una vertiente que no va a abordarse en el presente trabajo, véase Fernández Ramos, S. (2003). Los concejales y el acceso a la información. El derecho de los concejales de acceso a la documentación local, Granada, Comares.

18 Debe señalarse que la jurisprudencia ha incurrido de forma reiterada en el error de citar el apartado « $f$ » del art. 22 del Estatuto de Autonomía siendo que el apartado que hace referencia a este aspecto es el «k». 
2 de abril, Reguladora de las Bases del Régimen Local ${ }^{19}$, el Real Decreto 2568/1986, de 28 de noviembre, por el que se aprueba el Reglamento de Organización, Funcionamiento y Régimen Jurídico de las Entidades Locales, y demás normativa de desarrollo.

d) Un derecho de configuración legal

Teniendo en cuenta lo hasta ahora dicho, no cabe albergar ninguna duda, por más que la cuestión haya sido en ocasiones criticada ${ }^{20}$, de que el ius in officium del art. 23.2 CE se articula como un derecho de configuración legal. Así se ha constatado en la práctica normativa siendo, además, un extremo que el TC ha reconocido en su jurisprudencia de forma reiterada ${ }^{21}$. Los instrumentos normativos a los que, en su caso, corresponde regular y concretar el contenido de este derecho son (al margen de los matices que después se introducirán) tasados y ya han sido, en buena medida, desvelados en epígrafes anteriores. Así, por lo que respecta a los miembros de las entidades locales es la ya citada Ley de Bases de Régimen Local y su normativa de desarrollo. Y por lo que respecta a los parlamentarios (sean éstos estatales o autonómicos) son, como puede presumirse, los reglamentos de las asambleas legislativas respectivas; además, por supuesto, de los Estatutos de Autonomía, según se ha indicado ya. Tampoco puede dejar de señalarse a este respecto que la capacidad de las asambleas legislativas para controlar la tarea gubernamental a través de la solicitud de información cuenta en nuestro ordenamiento jurídico — tanto en su dimensión estatal como autonómica- con un refuerzo adicional en las leyes de gobierno. Así, en este punto, cabe hacer referencia, en el plano estatal, al art. 26.2 de la Ley 50/1997, de 27 de noviembre,

19 Según su art. 77: «Todos los miembros de las Corporaciones locales tienen derecho a obtener del Alcalde o Presidente o de la Comisión de Gobierno cuantos antecedentes, datos o informaciones obren en poder de los servicios de la Corporación y resulten precisos para el desarrollo de su función».

20 Véanse, por ejemplo, las reservas mostradas a este respecto en los trabajos de Biglino Campos, P. (1993). «Las facultades de los parlamentarios ¿son derechos fundamentales?». Revista de las Cortes Generales, n. ${ }^{\circ}$ 30, pp. 74-75; de Pulido Quecedo, M. (1992). El acceso a los cargos y funciones públicas. Un estudio del artículo 23.2 de la Constitución, Madrid, Civitas, p. 322; de Jiménez Campo, J. (1997), «Sobre los derechos fundamentales de los parlamentarios», en Pau i Vall, F. (coord.), Parlamento y Justicia Constitucional. IV Jornadas de la Asociación Española de Letrados de Parlamentos, Pamplona, Aranzadi, pp. 219-232; o de Santaolalla López, F., op. cit., pp. 120-121.

21 Véanse las SSTC 10/1983, FJ 2; 32/1985, FJ 3; 161/1988, FJ 7; 181/1989, FJ 4; 205/1990, FJ 5; 220/1991, FJ 5; 225/1992, FJ 1; 38/1999, FJ 2; 27/2000, FJ 4; 203/2001, FJ 2; 177/2002, FJ 3; 40/2003, FJ 2; 208/2003, FJ 4; 227/2004, FJ 2; 89/2005, FJ 2; 90/2005, FJ 2; 361/2006, FJ 2; 141/2007, FJ 3; 74/2009, FJ 3; 190/2009, FJ 2; 44/2010, FJ 3; 57/2011, FJ 2; 88/2012, FJ 2; 246/2012, FJ 4; 200/2014, FJ 4; 202/2014, FJ 3; 107/2016, FJ 4; 108/2016, FJ 4; 199/2016, FJ 3; 212/2016, FJ 3; 224/2016, FJ 2; 225/2016, FJ 2; 11/2017, FJ 3; 32/2017, FJ 4; 76/2017, FJ 3; 4/2018, FJ 3; 10/2018, FJ 3; así como los AATC 118/1999, FJ 2; 181/2003, FJ 2; 200/2004, FJ 3; y 85/2006, FJ 6. 
del Gobierno ${ }^{22}$; y, en el plano autonómico — a título meramente ejemplificativo—al art. 45.2 de la Ley 5/1983, de 30 de diciembre, de Gobierno Valenciano ${ }^{23}$.

En este sentido, la jurisprudencia contencioso-administrativa de los últimos años ha reforzado tales nociones $y$, adicionalmente, ha aportado algunos criterios interpretativos a los que interesa referirse. De entrada, merece particular mención que, en los casos en que los parlamentarios han fundamentado sus solicitudes de información alegando — complementariamente a su status de representantes - su derecho de acceso, en tanto que simples ciudadanos, a la documentación solicitada (invocando el art. 35, de la —ya derogada - Ley 30/1992, de 26 de noviembre, de Régimen Jurídico de las Administraciones Públicas y del Procedimiento Administrativo Común ${ }^{24}$ ), los tribunales han descartado (expresa o tácitamente) que, en el contexto de las relaciones gobierno-parlamento, sea apropiado realizar una petición de documentación sobre la base de dicha normativa ${ }^{25}$. Y, en este sentido, han entendido que tampoco podían operan los límites previstos en el art. 37.7 de la misma Ley 30/1992 26 invocados en ocasiones por la administración para fundamentar $-\mathrm{o}$, mejor dicho, para complementar- posturas negativas ante determinadas solicitudes de documentación ${ }^{27}$.

${ }^{22}$ En virtud del cual: «Todos los actos y omisiones del Gobierno están sometidos al control político de las Cortes Generales».

${ }^{23}$ En virtud del cual: «El Consell proporcionará a Les Corts los datos, informes o documentos que éstas precisen a través de la Presidencia de Les Corts. El Consell deberá facilitar la información o documentación solicitada en un plazo no superior a treinta días o manifestar las razones fundadas en derecho que lo impidan».

${ }^{24}$ Cuya actual correspondencia estaría, mutatis mutandis, en el art. 13 de la Ley 39/2015, de 1 de octubre, del Procedimiento Administrativo Común de las Administraciones Públicas, que, en lo relativo al acceso a la información, se remite a la Ley 19/2013, de 9 de diciembre, de transparencia, acceso a la información pública y buen gobierno.

${ }^{25}$ Véanse las STSJCV, 5..$^{a}$, de 28 de octubre de 2014, recurso 117/2014; STSJCV, 5. ${ }^{a}$, de 29 de octubre de 2014, recurso 95/2014; y STSJCV, $5 .{ }^{a}$, de 5 de noviembre de 2014, recurso 175/2014. Por su parte, en las STSJCV, 5. ${ }^{a}$, de 26 de febrero de 2014, recurso 298/2013; STSJCV, 5. ${ }^{a}$, de 5 de marzo de 2014, recurso 319/2013; y STSJCV, 5. ${ }^{a}$, de 10 de junio de 2014, recurso 549/2013, se observa que los diputados mencionan igualmente el art. 35 de la - ya derogada - Ley 30/92, pero invocando la condición de «interesados» en el procedimiento administrativo, lo cual constituye a todas luces un error puesto que, por un lado, se observa la inadecuación del precepto citado para apelar a esta figura (regulada en el art. 31 de la ley de entonces y no en el 35) y, por otro, resulta evidente (a la luz del contexto) que los demandantes no se refieren a la misma, sino al derecho de acceso a la información pública desde su condición genérica de ciudadanos. Sobre la distinción entre estas figuras como sujetos con derecho a información véase Razquin Lizárraga, M. M. (2018). «Límites del derecho de información de los diputados». Revista Española de Derecho Constitucional, n. ${ }^{\circ} 68$, p. 42.

${ }^{26}$ Dicho precepto establecía que: «El derecho de acceso será ejercido por los particulares de forma que no se vea afectada la eficacia del funcionamiento de los servicios públicos». Actualmente los límites del derecho de los ciudadanos de acceso a la información pública, archivos y registros se regulan en la Ley 19/2013, de 9 de diciembre, de transparencia, acceso a la información pública y buen gobierno.

${ }_{27}$ Véanse, entre otras, STSJCV, 5. , de 2 de abril de 2014, recurso 297/2013; STSJCV, 5. ${ }^{a}$, de 11 de junio de 2014, recurso 547/2013; y STSJCV, 5. ${ }^{a}$, de 7 de octubre de 2014, recurso 545/2013. 
En esta misma línea, también se ha descartado la operatividad de los límites establecidos en la legislación de transparencia — singularmente en el art. 18 e) de la Ley 19/2013, de 9 de diciembre, de transparencia, acceso a la información pública y buen gobierno ${ }^{28}$ — para denegar solicitudes de documentación a representantes políticos; si bien esto no quiere decir que la jurisprudencia no haya reconocido - tal y como veremos más adelante- a esta legislación una cierta relevancia dentro del ámbito de las solicitudes de documentación realizadas por parlamentarios.

Lo que es evidente es que la jurisprudencia contencioso-administrativa ha establecido una línea divisoria — con algún matiz al que después se hará referenciaentre dos dimensiones: de un lado, la normativa que se ocupa de la «configuración legal» del derecho de los representantes políticos a recabar documentación administrativa; $y$, de otro, la normativa que regula el derecho de los ciudadanos a acceder a este mismo tipo de información ${ }^{29}$. Y es que, en puridad, hablamos de dos categorías conceptualmente distintas. La que aquí interesa, esto es, la que afecta a los representantes políticos, posee un espacio propio claramente delimitado. Así lo ha explicado Edmundo Matía Portilla — letrado de las Cortes de Castilla y León_ con suma claridad expositiva:

la facultad que asiste a los representantes políticos de recabar de las Administraciones Públicas los datos, informes o documentos que, obrando en poder de estas últimas, precisan para el mejor cumplimiento de sus funciones representativas no deriva, ni encuentra su fundamento, en el artículo 105.b) de la Constitución Española (que establece el acceso de los ciudadanos a los archivos y registros administrativos), sino, como ya se ha dicho, en el derecho de sufragio pasivo consagrado en el artículo 23.2 de la Constitución (...) Cuando un parlamentario o un concejal hace uso de la facultad que le reconoce el Reglamento parlamentario o la Ley de Bases de Régimen Local, respectivamente, de solicitar información en poder de una Administración Pública que precisa para el ejercicio de su actividad política no efectúa esa petición en su condición genérica de ciudadano español, sino haciendo uso de su calidad de representante político. Está ejerciendo una facultad inherente a su ius in officium que encuentra su fundamento en las normas reglamentarias o legales que acabamos de citar y no en la Ley 19/2013, y cuya constricción o negación ilegítima supone una vulneración del artículo 23.2 de la Constitución. ${ }^{30}$

${ }^{28}$ Según este precepto: «Se inadmitirán a trámite, mediante resolución motivada, las solicitudes (...) Que sean manifiestamente repetitivas o tengan un carácter abusivo no justificado con la finalidad de transparencia de esta Ley». Pues bien, en la STSJCV, 5. , , de 4 de noviembre de 2016, recurso 284/2016, FD 3, se desecha expresamente este argumento utilizado para la denegación de una solicitud de documentación (si bien es cierto que la sentencia no dice que se trate de una legislación inaplicable al caso).

${ }_{29}$ Nótese que el TC, en uno de los supuestos reseñados anteriormente, había dicho que «el acto gubernativo recurrido ha sido adoptado frente a los recurrentes en su cualidad de miembros de una Asamblea Legislativa, es decir, de parlamentarios, y no en consideración a su condición de ciudadanos» (STC 220/1991, FJ 4).

${ }^{30}$ Matía Portilla, E. (2017). «Derecho a la información de los representantes políticos, protección de datos y transparencia». Revista Jurídica de Castilla y León, n. ${ }^{\circ}$ 42, p. 143. 
e) Un derecho reforzado por la legislación de transparencia y por la jurisprudencia del TJUE

Sin perjuicio de que, como antes se ha indicado, la legislación en materia de transparencia ${ }^{31}$ no opere directamente en el ámbito de los derechos de los representantes políticos — toda vez que, como se ha indicado, tiene una fundamentación distinta y se sitúa en otras coordenadas-, lo cierto es que la jurisprudencia contencioso-administrativa le ha reconocido una cierta función de fortalecimiento de aquéllos. En este sentido, obsérvense los dos siguientes pronunciamientos —cronológicamente expuestos- del TS y del TSJCV:

Ya al margen de las circunstancias propias de este litigio y como consideración de futuro, hay que decir que, tras la Ley 19/2013, de 9 de diciembre, de transparencia, acceso a la información pública y buen gobierno, y para la Comunidad Valenciana, tras la Ley $2 / 2015$, de 2 de abril, de transparencia buen gobierno y participación ciudadana de la Comunidad Valenciana, el derecho de los parlamentarios a la información pública no puede sino verse fortalecido. En efecto, a fin de que estén en condiciones adecuadas para hacer frente a la especial responsabilidad que se les ha confiado al elegirlos, habrán de contar con los medios necesarios para ello, los cuales en punto al acceso a la información y a los documentos públicos no sólo no podrán ser inferiores a los que tiene ya a su disposición cualquier ciudadano en virtud de esas leyes, sino que deben suponer el plus añadido imprescindible. (STS, Sala de lo Contencioso, Sección 7. ${ }^{\mathrm{a}}$, de 1 de junio de 2015, recurso 956/2014, FD 7) ${ }^{32}$

Téngase en cuenta que lo racional es permitir un absoluto control y supervisión de la totalidad de la actividad que ejerciten los Entes y Corporaciones que dispongan de poder público. Además de racional, hay exigencias normativas que lo imponen (Ley 19/2013, de 9 de diciembre) más un extenso corpus jurisprudencial que, de forma intensa, lo reclama. Éste procede de la doctrina emitida por el Tribunal Cons-

31 Entre la abundante bibliografía de referencia sobre el particular resultan, a mi juicio, especialmente clarificadores e ilustrativos los trabajos al respecto de Lorenzo Cotino Hueso. En concreto, sobre el vigente marco regulatorio estatal, pueden verse, entre otros, Cotino Hueso, L. (2015), «La nueva Ley de transparencia y acceso a la información», Anuario de la Facultad de Derecho (Universidad de Alcalá), n. ${ }^{\circ}$, pp. 241-256; o Cotino Hueso, L. (2014), «El derecho fundamental de acceso a la información, la transparencia de los poderes públicos y el gobierno abierto. Retos y oportunidades», en Valero Torrijos, J. y Fernández Salmeron, M. (coords.), Régimen jurídico de la transparencia del sector público: del Derecho de acceso a la reutilización de la información, Cizur Menor, Aranzadi, pp. 37-71; o también Cotino Hueso, L. (2013), «Derecho y «gobierno abierto». La regulación de la transparencia y la participación y su ejercicio a través del uso de las nuevas tecnologías y las redes sociales por las Administraciones públicas. Propuestas concretas», Revista Aragonesa de Administración Pública, n. ${ }^{\circ}$ extra 14, (Ejemplar dedicado a: Transparencia, participación ciudadana y Administración pública en el siglo XXI), pp. 51-92. Y, desde una perspectiva más amplia, entre otros trabajos suyos, puede verse Cotino Hueso, L. (2017), «El reconocimiento y contenido internacional del acceso a la información pública como derecho fundamental», Teoría y Realidad Constitucional, n. ${ }^{\circ} 40$, pp. 279-316.

32 Este mismo pasaje vuelve a aparecer en las dos siguientes resoluciones del TS: STS, Sala de lo Contencioso, Sección 7. a, de 15 de junio de 2015, recurso 3429/2013, FD 7; y STS, Sala de lo Contencioso, Sección 7. ${ }^{a}$, de 15 de junio de 2015, recurso 2165/2013, FD 8. 
titucional y Sala 3. del Tribunal Supremo. (TSJCV, 5. a, de 4 de noviembre de 2016, recurso 284/2016, FD 3)

A este respecto, el ya citado Edmundo Matía Portilla ha considerado que la trascendencia de esta normativa para el derecho de los representantes políticos a recabar documentación administrativa radica, esencialmente, en que la aprobación de ésta:

ha venido a recordar a todos los operadores jurídicos (...) que la publicidad de las actuaciones y comportamientos de los poderes públicos, en cuanto condición absolutamente necesaria para la pervivencia de una sociedad libre y democrática, debe prevalecer en caso de conflicto frente a otros derechos o bienes también protegidos constitucionalmente ordenados a la preservación de intereses puramente individuales. Y la consecuencia de este entendimiento no puede ser otra que una revalorización y fortalecimiento del derecho de nuestros representantes políticos a acceder a la información obrante en poder de las Administraciones Públicas como instrumento necesario para el ejercicio del ius in officium que les garantiza el artículo 23.2 de la Constitución. ${ }^{33}$

Cuestión distinta es si el diputado puede utilizar, paralelamente, ambas vías de acceso a la información pública, es decir, la prevista en el correspondiente reglamento parlamentario (ligada al derecho fundamental del art. 23.2 CE) y la establecida en la legislación de transparencia aplicable al caso (derivada del derecho no fundamental del art. 105 b) CE). Un doble cauce posible en opinión de Emilio Guichot Reina ${ }^{34}$ y de Martín María Razquin Lizárraga ${ }^{35}$; siendo, además, una práctica aceptada en el ámbito de la Unión Europea (véase la STJUE de 3 de julio de 2014, asunto C-350/12 $\mathrm{P}$, a propósito de una petición de información presentada por una diputada del Parlamento Europeo al Consejo).

Al hilo de esta última consideración, si bien desde una perspectiva más general, la jurisdicción contencioso-administrativa (véase, en concreto, la STSJCV, 5. a de 19 de junio de 2013, recurso 30/2012, FD 5 O) ha hecho mención expresa de que hay jurisprudencia del Tribunal de Justicia de la Unión Europea que «coadyuva» a respaldar los derechos de los parlamentarios a recabar documentación administrativa. En este sentido, se invoca la sentencia del Tribunal de Justicia, Gran Sala, de 1 de julio de 2008, dictada en los asuntos acumulados C-39/05 y C/52/05, caso Maurizio Turco. Ciertamente, el TSJCV advierte que esta jurisprudencia se ubica «en un plano jurídico distinto pero relacionado» con el que aquí se estudia. Aún así, no cabe duda de que con ello se abre una (aparente) línea de convergencia de gran interés entre jurisprudencias que cabrá estudiar con mayor atención y detalle en lo sucesivo.

33 Matía Portilla, E., op. cit., p. 147.

${ }^{34}$ Guichot Reina, E. (2017). «El derecho de los representantes políticos a la información y la nueva normativa sobre transparencia y acceso a la información pública. Revista de Estudios de la Administración Local y Autonómica», n. ${ }^{\circ} 8$, pp. 27-48.

35 Razquin Lizárraga, M. M., op. cit., p. 43. 
f) ¿Un derecho ilimitado?

Con carácter general la jurisprudencia constitucional ha señalado —en numerosas ocasiones - la idea de que «no cualquier acto que infrinja la legalidad del ius in officium lesiona el derecho fundamental, pues sólo poseen relevancia constitucional a estos efectos los derechos o facultades atribuidos al representante que pertenezcan al núcleo de su función representativa parlamentaria, como es, indudablemente, el ejercicio de la función legislativa o de control de la acción del Gobierno» (STC 190/2009, FJ 2, por citar una entre tantas $\left.{ }^{36}\right)$.

Pues bien, al margen de que esta doctrina adolezca de cierta «ambigüedad» —en palabras de Eduardo Mancisidor Artaraz ${ }^{37}$ - ya que no clarifica cuáles son, en concreto, esos derechos que «poseen relevancia constitucional» a los efectos descritos; no cabe duda de que el derecho de los parlamentarios a recabar documentación administrativa se inserta —a la luz de cuanto hasta ahora se ha dicho- dentro de ese núcleo de la función representativa. En consecuencia, toda cortapisa que impida su ejercicio o satisfacción constituye una potencial lesión del derecho fundamental.

Sin embargo, y como anteriormente se ha anticipado, el TC ha expresado que «la denegación o incompleta satisfacción de una pregunta o petición de información formuladas por parlamentarios no supone, por sí misma, la vulneración del derecho fundamental (...) que no comprende el derecho a una respuesta con un concreto contenido» (STC 220/1991, FJ 5). De este modo, vemos que el TC (que, ciertamente, no ha profundizado lo suficiente en la cuestión al no haber resuelto prácticamente controversias sobre esta específica manifestación del ius in officium) ha clarificado que el derecho de los parlamentarios a recabar información no es un derecho absoluto en la medida en que puede verse insatisfecho sin que automáticamente deba entenderse vulnerado. Una lectura jurisprudencial que no hace sino aplicar a este supuesto el criterio básico de que todos los derechos son limitados y con mayor razón los derechos de configuración legal.

Por su parte, durante los últimos años, los tribunales contencioso-administrativos han partido igualmente del presupuesto de que no se trata de un derecho absoluto. En este sentido, han afirmado que una razón justificada «podría prevalecer al no ser ilimitado el derecho a la información de los parlamentarios» (véanse, entre otras, la STSJCV, 5. , , de 17 de diciembre de 2014, recurso 187/2014, FD 4; o la STSJCV, 5. , de 14 de julio de 2015, recurso 989/2014, FD 4). Desde esta misma perspectiva, se

36 No obstante, véanse también las SSTC 38/1999, FJ 2; 27/2000, FJ 4; 107/2001, FJ 3; 203/2001, FJ 2; 64/2002, FJ 2; 142/2002, FJ 1; 177/2002, FJ 3; 15/2003, FJ 5; 40/2003, FJ 2; 208/2003, FJ 4; 89/2005, FJ 2; 90/2005, FJ 2; 361/2006, FJ 2; 141/2007, FJ 3; 39/2008, FJ 5; 74/2009, FJ 3; 190/2009, FJ 2; 44/2010, FJ 3; 57/2011, FJ 2; 200/2014, FJ 4; 201/2014, FJ 3; 202/2014, FJ 3; 1/2015, FJ 3; 23/2015, FJ 3; 199/2016, FJ 3; 212/2016, FJ 3; 224/2016, FJ 2; 225/2016, FJ 2; 11/2017, FJ 3; 32/2017, FJ 4; 71/2017, FJ 6; 76/2017, FJ 3; 4/2018, FJ 3; 10/2018, FJ 3; así como los AATC 118/1999, FJ 2; 181/2003, FJ 2; 200/2004, FJ 3; 85/2006, FJ 6.

37 Mancisidor Artaraz, op. cit., pp. 351-352. 
ha hablado de la posible existencia de «motivos fundados y legítimos» que podrían limitar el alcance del derecho en cuestión (STSJCV, 5. a , de 29 de octubre de 2014 , recurso 95/2014, FD 2).

Ahora bien, en la práctica, la jurisdicción contencioso-administrativa ha restringido ostensiblemente el margen de tolerancia ante los supuestos de —lo que el TC ha denominado - «denegación o incompleta satisfacción de una pregunta o petición de información formuladas por parlamentarios». Hasta tal punto ha sido así, que únicamente en una de las casi cuarenta causas judiciales iniciadas durante la última década por este motivo en el ámbito de la Comunitat Valenciana, los tribunales contencioso-administrativos han apreciado legítima y ajustada a derecho una denegación de documentación por parte de la administración autonómica.

De la lectura de este reciente corpus jurisprudencial se deduce que el derecho en cuestión exige ser satisfecho en la generalidad de los casos, siendo excepcionales las ocasiones en las cuales puede verse frustrado. De ahí que las resoluciones denegatorias de documentación hayan sido declaradas contrarias a derecho por la jurisdicción contencioso-administrativa de forma constante y abrumadoramente mayoritaria. Ahora bien, mientras que durante la última década ha habido casos en los cuales la motivación de la denegación por parte de la administración ha sido inexistente, incongruente o a todas luces insuficiente $-\mathrm{y}$, por lo tanto, la consecuente decisión jurisdiccional a propósito de tales supuestos ha sido automática ${ }^{38}$ - , ha habido otros en los que se han alegado motivos que, al menos de entrada, ha habido que detenerse a estudiar y a desgranar e, incluso, en una ocasión - como ya se ha anticipado- a aceptar. Este segundo grupo de supuestos es el que ha permitido que se hayan ido perfilando una serie de criterios jurisprudenciales acerca de los límites del derecho de los parlamentarios a recabar documentación administrativa.

El análisis de toda esta casuística se aborda en el subsiguiente epígrafe. Sin embargo, antes de descender a su examen pormenorizado, es pertinente esbozar de forma breve y esquemática cuál es la pauta general que ha trazado la jurisprudencia contencioso-administrativa en torno a los límites de este derecho de los parlamentarios.

Pues bien, el primero y más claro de tales límites, según la jurisprudencia, es todo aquel que marque expresamente el ordenamiento jurídico (y aquí, en caso de divergencias interpretativas, siempre se tiende a favorecer aquella que satisfaga el derecho del diputado). Y, debe remarcarse, este criterio, además de a previsiones normativas

38 Los casos que cabría referir aquí son abundantes pero, a título meramente ejemplificativo, cabe mencionar los resueltos por las STSJCV, 5. ${ }^{\text {, }}$, de 13 de mayo de 2014, recurso 389/2013; STSJCV, 5. ${ }^{\text {, }}$ de 20 de mayo de 2014, recurso 483/2013; STSJCV, 5. , de 20 de mayo de 2014, recurso 449/2013; STSJCV, 5. ${ }^{\text {, }}$, de 4 de junio de 2014, recurso 507/2013; STSJCV, 5. ${ }^{\text {, }}$ de 24 de septiembre de 2014, recurso 116/2014; STSJCV, 5. ${ }^{\text {, }}$, de 28 de octubre de 2014, recurso 117/2014; STSJCV, 5. ${ }^{\text {, }}$, de 5 de noviembre de 2014, recurso 175/2014; STSJCV, 5. a, de 12 de noviembre de 2014, recurso 210/2014; STSJCV, 5. ${ }^{a}$, de 21 de enero de 2015, recurso 657/2014; STSJCV, 5. ${ }^{a}$, de 25 de marzo de 2015, recurso 418/2013; y STSJCV, 5. ${ }^{\text {, }}$, de 14 de julio de 2015, recurso 989/2015. 
concretas, se hace extensible a la interpretación que de ellas hayan hecho los tribunales; por ello se ha dicho que el límite podrá venir dado por una «previsión normativa y/o aval jurisprudencial» (en este sentido, por ejemplo, la STSJCV, 5. a, de 24 de septiembre de 2014, recurso 116/2014, FD 2).

Por otra parte, están los límites — más abstrusos_ derivados de la imposibilidad física de proveer al parlamentario de la documentación solicitada (por no existir, por haber desaparecido o por otra razón distinta), ante los cuales, como a continuación se verá, los tribunales contencioso-administrativos muestran grandes reticencias. En este sentido, parece que no es suficiente con una motivación de los hechos y las razones que han impedido a la administración proveer al parlamentario de la concreta información solicitada; e, incluso, parece que tampoco lo es sustituir dicha documentación (que no es posible aportar por la razón que concurra en cada caso) por una relación o informe alternativo que permita al representante político formarse una opinión al respecto de la cuestión de que se trate.

\subsection{Situaciones potencialmente conflictivas derivadas del ejercicio de este derecho}

A continuación se exponen nueve escenarios reales y de especial complejidad que se han dirimido en los tribunales contencioso-administrativos a lo largo de los últimos años $^{39}$. El propósito de las páginas que siguen es conocer sus aspectos clave y tratar de extraer de los mismos elementos interpretativos de interés y utilidad.

a) ¿Qué pasa cuando la documentación que se solicita se halla afectada por un secreto sumarial?

En primer lugar, cabe precisar que la jurisprudencia constitucional ya clarificó tempranamente que «el secreto del sumario no significa, en modo alguno, que uno o varios elementos de la realidad social (...) sean arrebatados a la libertad de información, en el doble sentido de derecho a informarse y derecho a informar, con el único argumento de que sobre aquellos elementos están en curso unas determinadas diligencias sumariales. De ese modo, el mal entendido secreto del sumario equivaldría a

39 Desde la perspectiva de un análisis casuístico de otras realidades autonómicas —eso sí, ninguna de ellas judicializada como ha sido el caso de la valenciana- tienen interés los siguientes trabajos: Auzmendi del Solar, M. (2011). «El derecho de acceso a la información de los diputados», en Pau i Vall, F. (coord.), Parlamento y Diputado. XVII Jornadas de la Asociación Española de Letrados de Parlamentos, Madrid, Tecnos, 2011, pp. 265-279; Folchi, I. (2008). «El dret dels diputats a obtenir informació». Col.lecció papers de relacions Govern-Parlament: recull annual, n. ${ }^{\circ}$ 1, pp. 64-107; Fernández Segado, F. (1995). «El derecho a la obtención de información de los diputados del Parlamento de Galicia: reflexiones en torno al artículo 9. 1 y 2 del Reglamento del Parlamento». Revista de las Cortes Generales, n. 34 (1995), pp. 127-172; Soriano Hernández, E. (1992). «El derecho a la información de los diputados: el artículo 7 del Reglamento de las Cortes Valencianas». Revista de las Cortes Generales, n. ${ }^{\circ} 26$, pp. 43-68. 
crear una atípica e ilegítima «materia reservada» sobre los hechos mismos acerca de los cuales investiga y realiza la oportuna instrucción el órgano judicial, y no sobre «las actuaciones» del órgano judicial que constituyen el sumario» (STC 13/1985, FJ 3).

Pues bien, partiendo de estas premisas, y en aplicación de dicha doctrina a un supuesto en el que dos diputados de Les Corts solicitaron una documentación afectada por secreto sumarial, el TSJCV consideró que: «el secreto sumarial afectaría tan sólo si la petición de información lo fuera de documentos que forman parte del propio sumario y sólo de él, pero esta circunstancia no es predicable de aquéllos sobre los que se solicita información porque dicha documentación preexistió al sumario y desde luego, hayan o no sido incorporados al mismo, su naturaleza pública es previa, por tanto, no es conforme a derecho la negativa parcial contenida en el acto cuya constitucionalidad se cuestiona» (STSJCV, 5. a, de 29 de abril de 2011, recurso 659/2009, FD 3). Y, posteriormente, el TS confirmo esta interpretación, entendiendo que:

El secreto sumarial alegado en términos bien indeterminados no es razón que justifique la negativa a facilitar datos de unos contratos administrativos que nada dicen del proceso penal pues son previos a él y, ciertamente, no tienen por sí mismos carácter secreto sino todo lo contrario. La investigación sumarial es secreta siempre para terceros y, en algunos casos, además, para aquél o aquellos contra los que se dirige si así lo dispone el Juez instructor. No ha explicado la Generalitat Valenciana, ni siquiera ahora, de qué secreto se trata ni ha dicho por qué ha de verse afectada por él, en términos que exijan no hacerla, la comunicación de la información que se le pidió sobre unos contratos suscritos con anterioridad, especialmente cuando la Sala de Valencia dijo en su sentencia que su aportación a los parlamentarios no interfería la investigación sumarial. (STS, Sala de lo Contencioso, Sección 7. a, de 25 de febrero de 2013, recurso 4268/2011, FD 7) $)^{40}$

b) ¿Qué pasa cuando la documentación que se solicita es un informe o documento de trabajo concebido para la exclusiva circulación interna en la administración?

En este punto, la jurisprudencia del TSJCV de los últimos años se ha mostrado contundente y no ha aceptado el pretexto del carácter interno de la documentación solicitada como fundamento para su denegación, que ha sido calificado, sin ambages, de «argumento carente de legitimidad» (STSJCV, 5. a , de 14 de enero de 2014, recurso 58/2013, FD 4). A este respecto, se ha subrayado a menudo la idea de que «no existe aquí margen para la discrecionalidad administrativa», pues la única razón que podría justificar una negativa de este tipo de documentación sería si mediara «una certera, ineludible, previsión normativa que así lo disponga». Y es que, según se ha reiterado, la contestación a una petición parlamentaria de esta índole «viene dada por

${ }^{40}$ El mismo caso volvió a darse, con idéntica resolución, en la STSJCV, 5. a, de 11 de marzo de 2014 , recurso $142 / 2013$. 
la normativa aplicable y no por la decisión autónoma (por tener ribetes discrecionales)» de la administración (véase, entre otras, la STSJCV , 5. a , de 19 de junio de 2013 , recurso 30/2012, FD 5, 1$)^{41}$.

Particular mención merecen en este apartado — debido a su reiteración- aquellos casos en los que se ha solicitado copia íntegra de los estudios trimestrales de opinión pública en el ámbito de la Comunitat Valenciana —bien elaborados por la propia administración, bien elaborados por empresas con las que ésta ha contratado a tal efecto- y que han sido denegados alegando, por un lado, que poseen «carácter auxiliar para la evaluación y definición de políticas públicas» sin abordar «en ningún caso cuestiones relacionadas con la intención de voto ni con las valoraciones personales de líderes políticos»; y, por otro, que se trata de información que será pública transcurrido un cierto tiempo en aplicación de la legislación estatal y autonómica en materia de transparencia. Pues bien, en todos estos supuestos la denegación de documentación fue declarada contraria a derecho por parte de la jurisdicción contencioso-administrativa (STSJCV, 5. a, de 30 de mayo de 2014, recurso 548/2013; STSJCV, 5. ${ }^{\text {, }}$, de 10 de junio de 2014, recurso 549/2013; STSJCV, 5. ${ }^{\text {, }}$ de 10 de junio de 2014, recurso 542/2013; STSJCV, 5. , de 11 de junio de 2014, recurso 547/2013; STSJCV, 5. ${ }^{a}$, de 30 de junio de 2014, recurso 543/2013; STSJCV, 5. ${ }^{a}$, de 29 de septiembre de 2014, recurso 546/2013; y STSJCV, 5. ${ }^{a}$, de 7 de octubre de 2014, recurso 545/2013).

Por su parte, el TS también ha tenido ocasión de pronunciarse al respecto y ha ratificado la doctrina emanada del TSJCV considerando que el «carácter genérico e indeterminado» de este tipo de motivación denegatoria por parte de la administración «le priva de toda virtualidad justificante» (STS, Sala de lo Contencioso, Sección 7.a, de 1 de junio de 2015, recurso 956/2014, FD 7). Y en una resolución posterior volvió a reiterar este criterio cuando afirmó que «la justificación ofrecida es meramente formal y, por tanto, carece de toda virtualidad para fundamentar la denegación» (STS, Sala de lo Contencioso, Sección 7.a, de 15 de junio de 2015, recurso 3429/2013, FD 7).

${ }^{41}$ No puede dejar de señalarse que, en este concreto supuesto, el criterio del TSJCV fue contrario al del Consell Jurídic Consultiu de la Comunitat Valenciana, que —a raíz de una consulta a colación de este asunto - manifestó que: «el citado informe es un documento de trabajo de uso interno, que sólo tiene validez en el ámbito de decisión de quienes ostentan cargos de responsabilidad en el día a día de Radiotelevisión Valenciana. Su publicación no es procedente, puesto que la información que contiene ha de ser completada y comparada con la de esos otros análisis e informes internos y externos que obran en posesión de la dirección del Grupo hasta generar el Plan de Actuación Definitivo de RTVV. En ese momento, como siempre ha sido y cumpliendo con todos los requisitos legales de tiempo y forma, el plan se someterá a debate y aprobación por parte de los miembros del Consejo de Administración, competente en materia de personal. Cuando se cuente con el visto bueno de este órgano de gestión, el Plan será accesible para todos». 
c) ¿Qué pasa cuando la documentación que se solicita carece de soporte escrito?

En este punto, un ejemplo recurrente ha sido el de los contratos menores, puesto que su tramitación sólo exige la aprobación del gasto y la incorporación de la factura correspondiente (salvo en el de obras, que exige el presupuesto de obras y proyecto, en su caso). A este respecto el TSJCV tiene dicho lo siguiente: «no vamos a negar que la petición es de los contratos y estos, documentalmente no existen, con lo que la negativa del Sr. Conseller aparecería formalmente justificada en derecho (...) [pero] lo que no escapa a nadie es que la petición se formula para conocer los contratos menores que durante el período de tiempo señalado, se han llevado a cabo con la citada empresa y este dato sí es posible facilitarlo y no hay razón jurídica alguna para no haberlo hecho, incidiendo con ello en la vulneración denunciada» (véase, entre otras, la STSJCV, 5. ${ }^{\text {, }}$, de 27 de marzo de 2014, recurso 197/2013, FD3) ${ }^{42}$.

Es importante subrayar — pues así lo ha hecho el TSJCV_ que, en este tipo de supuestos, no se enjuicia la adecuada formalidad seguida en su momento en la tramitación de los expedientes afectados (que es precisamente lo que trata de someter a control el o los parlamentarios solicitantes), sino la adecuación de la respuesta ofrecida por la administración en el marco de su control parlamentario. Por ello las respuestas consistentes en justificar la actuación administrativa del pasado que pretende controlarse desde el parlamento, no se consideran idóneas, puesto que lo que se pide no es una justificación o excusatio, sino la información en sí. Al respecto el TSJCV ha reiterado la idea de que:

la cuestión no es la relativa a la adecuada formalidad seguida en la tramitación de los expedientes y mucho menos la referencia al control posterior, dentro de la propia Administración, que nada tiene que ver con el control parlamentario de que se trata, la cuestión es si esta respuesta es la adecuada o no lo es y en este último caso si entraña la vulneración constitucional denunciada. ${ }^{43}$

Al margen de los casos sobre contratación menor, pero también en relación con la problemática de la (presunta) inexistencia de la documentación solicitada, el TSJCV desestimó en una ocasión el argumento sustentado por la Generalitat de que un determinado informe de auditoría interna «no existía como tal»; ya que al no negarse la existencia de la auditoría misma, era posible facilitar la información requerida al margen de otras consideraciones (STSJCV, 5. a , de 20 de septiembre de 2016 , recurso 792/2015, FD 3). Desde esta perspectiva, también reviste innegable interés — si bien sería excesivo detenerse a exponerlo- el caso enjuiciado en la STSJCV, 5. ${ }^{\text {a }}$, de 28 de febrero de 2017, recurso 161/2016, sobre la inexistente documentación asociada a una línea de subvención nominativa de la ley autonómica de presupuestos.

${ }^{42}$ Este mismo criterio volvió a sostenerse en la STSJCV, 5. ${ }^{\text {, }}$, de 9 de abril de 2014, recurso 427/2013, FD 3.

${ }^{43}$ STSJCV , 5. ${ }^{\text {a }}$, de 27 de marzo de 2014, recurso 197/2013, FD 3; STSJCV, 5. a, de 9 abril de 2014 , recurso 427/2013, FD 3; STSJCV, 5. a, de 21 de enero de 2015, recurso 657/2014, FD 3. 
Por último, cabe mencionar que, con carácter reciente, se han dado casos en los que el TSJCV, aún habiendo declarado inaceptable y contrario a derecho el argumento de la inexistencia de la documentación solicitada; ha terminado reconociendo, con posterioridad, la imposibilidad material para la administración de proveer al diputado la información solicitada. En este sentido, por ejemplo, el ATSJCV, $5 .^{\text {a }}$, de 25 de abril de 2017, FD 1, (vinculado a la anteriormente mencionada STSJCV, 5. a , de 20 de septiembre de 2016, recurso 792/2015, relativa a la auditoría), dijo lo siguiente:

Examinada la sentencia dictada en los presentes autos y la información facilitada por la Administración demandada, procede apreciar la causa de imposibilidad material de ejecución de la sentencia (...), en tanto que, de la documentación aportada por la Administración demandada con posterioridad a la fecha de la sentencia, consistente en informe de la Interventora General de la Generalidad Valenciana «no se ha efectuado hasta la fecha ninguna auditoría interna» de la actividad administrativa o económico-financiera correspondiente exclusivamente a la Conselleria de Justicia, Administración Pública, Reformas Democráticas y Libertades Públicas. ${ }^{44}$

d) ¿Qué pasa cuando la documentación que se solicita está afectada por la protección de datos de carácter personal?

Pese a tratarse de un motivo de denegación frecuentemente alegado por parte de las administraciones públicas ${ }^{45}$, lo cierto es que no nos encontramos ante un fenómeno que haya tendido a la judicialización. De hecho, de entre toda la casuística aquí examinada, tan sólo en un supuesto se ha visto implicada - y ni siquiera de forma directa - la protección de datos de carácter personal. Y, además, curiosamente, se trata del único caso en que la jurisdicción contencioso-administrativa ha fallado en favor de la administración autonómica.

Concretamente, en la STSJCV, 5. a, de 15 de septiembre de 2017, recurso 972/2016, se consideró ajustada a derecho la denegación por parte de la administración de una copia del «Plan de Control Tributario aprobado para 2016». El TSJCV constató que, en este supuesto, había límites expresos en el ordenamiento jurídico que avalaban dicha denegación: en concreto los artículos 95 (relativo al carácter reservado de los datos con trascendencia tributaria); y 116 (que dispone expresamente que el Plan de control tributario «tendrá carácter reservado, aunque

44 Esta anomalía procesal se examina desde una óptica general en Gómez Ferrer Rincón, R. (2008). La imposibilidad de ejecución de sentencias en el proceso contencioso-administrativo, Madrid, Aranzadi.

45 Véase Martínez Martínez, R. (2015). «Transparencia en la acción política en la Comunidad Valenciana. Las limitaciones de acceso a la información a los representantes de la oposición», en Jareño Leal, A. (dir.), Corrupción pública. Cuestiones de política criminal (II): la Comunitat Valenciana, Madrid, Iustel, pp. 179-207. 
ello no impedirá que se hagan públicos los criterios generales que lo informen») de la Ley 58/2003, de 17 de diciembre, General Tributaria. Asimismo, se invocó, como precedente jurisprudencial, la STS, Sala de lo Contencioso-Administrativo, 2. ${ }^{a}$, de 3 de enero de 2001, recurso de casación 7741/1995. Sin embargo, por más que en este caso los datos de carácter personal se viesen implicados como telón de fondo, lo cierto es que la administración autonómica no denegó la documentación solicitada argumentando la necesidad de salvaguardar dicha información sensible, sino que invocó un mandato legal expreso que resultaba de indiscutible aplicación al supuesto planteado.

Sea como fuere, en este punto, son de gran interés las reflexiones que ha aportado al debate Edmundo Matía Portilla — recuérdese, letrado de las Cortes de Castilla y León- ${ }^{46}$. Y es que, a su juicio, cuando el derecho de participación política entra en conflicto con el derecho a la protección de datos y resulta necesario proceder a su ponderación,

habrá de tenerse muy presente al realizar ésta la dimensión institucional del primero (en su condición de garantía ordenada a la limitación del poder) y su directa conexión con el principio democrático. Posición ésta que contrasta con los intereses puramente individuales que viene proteger el derecho a la autodeterminación informativa contemplado en el artículo 18.4 de la Constitución. Este debería ser a nuestro juicio, un punto de partida inexcusable tanto para el legislador como para los operadores jurídicos, de modo que el desarrollo legislativo de la libertad informática llevado a cabo por la LOPD, así como la interpretación y aplicación que de ésta se haga, tendrían que respetar escrupulosamente las exigencias que se derivan del principio democrático. ${ }^{47}$

Así pues, como puede verse, según su parecer, «la participación política posee, con carácter general, un valor preferente al derecho a la protección de datos ${ }^{48}$. Un punto de vista (desarrollado prolijamente en sus trabajos) que, por lo demás, ha sido expresado con anterioridad por otros autores como Ricard Martínez Martínez ${ }^{49}$, Francisco Fernández Segado ${ }^{50}$, Ricardo Martín Morales ${ }^{51}$ o — con algunos maticesMontserrat Auzmendi del Solar ${ }^{52}$.

46 Véase Matía Portilla, E. (2016). «Protección de datos personales y principio democrático: el derecho a la información de los representantes políticos», en Rubio Llorente, F. et al. (coords.), La Constitución política de España. Estudios en bomenaje a Manuel Aragón Reyes, Madrid, CEPC, pp. 747-770; así como el trabajo más reciente del mismo autor que ya se ha citado anteriormente (notas 30 y 33 ).

47 Matía Portilla, E., op. cit., p. 136.

48 Ibidem.

49 Martínez Martínez, R., op. cit., p. 181.

50 Fernández Segado, F., op. cit., p. 165.

51 Martín Morales, R. (1994). El derecho fundamental al honor en la actividad política, Granada, Universidad de Granada, p. 211.

52 Auzmendi del Solar, M., op. cit., p. 273. 
e) ¿Qué pasa cuando la documentación que se solicita involucra «cláusulas de confidencialidad» de un contrato público?

La jurisdicción contencioso-administrativa ha partido del presupuesto de que «es inadmisible y contradictorio hablar de confidencialidad» en materia de contratación pública; no obstante, ha aceptado que ésta podría tener cabida, a lo sumo, si se tratara «de documentos que contienen datos con repercusión exclusiva en el sector privado, como pudieran ser aquellos que afectan a secretos industriales de una de las partes contratantes» (STSJCV, 5. ${ }^{\mathrm{a}}$, de 18 de febrero de 2014, recurso 120/2013, FD 3).

Con relación a este tema, también se ha entendido del todo ilegítima la denegación de informes (bien elaborados por la propia administración, bien por empresas consultoras externas) bajo el pretexto de que podrían afectar a ulteriores procesos de licitación por contener información relevante al respecto. La jurisprudencia ha clarificado en este punto que «un futuro proceso de licitación (...) en modo alguno es incompatible ni puede enervar el derecho recogido en el citado artículo 23 CE» (STSJCV, 5. ${ }^{a}$, de 27 de junio de 2014, recurso 482/2013, FD 3).

f) ¿Qué pasa cuando la documentación que se solicita está en fase de elaboración, es decir, se trata de informes o procedimientos en curso?

Ha sido frecuente que la administración autonómica haya denegado documentación alegando que la misma «se encuentra en una avanzada fase de desarrollo y que, más adelante se dará información detallada sobre la misma». Ante tales supuestos, la jurisdicción contencioso-administrativa ha considerado — sin excepción- que se trata de una «negativa carente de legitimidad» (STSJCV, 5. a , de 26 de febrero de 2014, recurso 298/2013; STSJCV, 5. a, de 5 de marzo de 2014, recurso 319/2013; STSJCV, 5. a , de 2 de abril de 2014, recurso 297/2013). Con mayor prolijidad, el TSJCV ha dicho a este respecto lo siguiente:

[Que la Administración señale que] el expediente se encuentra en fase previa y que una vez sea remitido a las Cortes, tendrán acceso a toda la documentación (...) entraña una negativa abierta a facilitar dicha documentación. Es evidente que cuando se remita a las Cortes tendrán acceso, pero estamos ante una petición de las Cortes al Gobierno, que puede negarse por motivos fundados, para obviar el conocimiento actual que se le está solicitando de determinada documentación que ya obra en su poder - $\mathrm{O}$ al menos, no se indica que no sea así - y en la medida en que no facilita esos motivos fundados y legítimos, debemos declarar la existencia de vulneración constitucional en dicha negativa a facilitar los datos solicitados por el demandante, a que viene obligado el órgano requerido, y en tales términos procede la estimación del recurso interpuesto. (STSJCV, 5. a, de 29 de octubre de 2014, recurso 95/2014, FD 2) 
g) ¿Qué pasa cuando la documentación que se solicita es ingente (y a menudo con localización dispersa)?

Por lo que respecta a aquellas situaciones en las cuales la cantidad de información que se ha solicitado es muy abundante, la doctrina del TSJCV es nítida:

No se niega que las peticiones tal y como vienen planteadas pueden ser muy voluminosas, pero este no es un argumento para su denegación ni siquiera al amparo de la norma que se esgrime [art. 37 de la derogada Ley 30/1992] que si bien no está pensada para este supuesto — sino para el acceso público general— sí puede ser valorado a efectos, por ejemplo, de una excesiva generalidad en la petición, pero no existe generalidad en la misma sino profusión, cuestión distinta que tampoco justifica en derecho una negativa, aunque pudo la Administración Autonómica solicitar mayor precisión o pedir aclaración al efecto, ninguno de cuyos supuestos ha llevado a cabo más allá de la remisión a la conclusión del plan que es, como decimos, una negativa. (STSJCV, de 2 de abril de 2014, FD 3)

Al hilo de esta cuestión, también cabe preguntarse si es válido sostener, como ha hecho la administración autonómica valenciana en alguna ocasión, que no es posible facilitar la ingente cantidad de documentación solicitada ya que ello entrañaría una «enorme dificultad» en la medida en que «haría falta un trabajo y número de personas que supondría dejación de funciones que repercutiría en el funcionamiento normal de los servicios». Pues bien, nuevamente ante dicha reserva, la doctrina del TSJCV es clara:

No cabe duda de lo poderosos que son los argumentos de dicha respuesta (...) que se refiere a casi tres millones de facturas y a la dispersión de su archivo por diversas circunstancias, ahora bien, dos argumentos se oponen a la trascendencia que esta respuesta puede tener en los términos pretendidos por la Administración:

El primero de ellos, que del propio informe-base de la actuación administrativa impugnada se desprende que ese ingente número de facturas «...constan registradas en los sistemas informáticos competencia de esta subdirección General...» lo que implica la posibilidad de soporte informático cuya característica, a los efectos pretendidos, es precisamente que el ingente volumen pase a un segundo término no tratándose de facturas fotocopiadas, con la consecuencia asimismo de que ya no hace falta un gran número de funcionarios durante gran número de horas dedicados a ello, como afirma la Administración.

El segundo, que precisamente por estar registradas informáticamente y abarcar la petición a todas las facturas correspondientes al período de tiempo señalado y de todas las Consellerías, hace innecesaria labor de selección alguna, simplificando la búsqueda. Por otra parte, la concreción que se le solicita a la parte hoy demandante es inviable salvo la temporal, es decir, indudablemente podría la parte actora haber limitado el período solicitado pero por razones que no corresponde a este órgano jurisdiccional enjuiciar, su interés abarca dicho período y siempre pudo la Administración proceder escalonando la respuesta temporalmente y si ello no satisfacía al demandante, estaríamos ante una cuestión distinta a la sometida en el presente recurso 
y si la concreción que se le requiere no es temporal (...) le es imposible acotar por conceptos si desconoce a qué conceptos se ha podido destinar el importe de las cajas fijas, incluso si los mismos no vienen revestidos de la apariencia más insospechada por su presunta finalidad más o menos privada, sino a una finalidad pública (como la compra de medicamentos en Hospitales con el importe de las cajas fijas), el hecho de tratarse de fines no previstos para estas cantidades, impiden a los representantes políticos pedir en forma adecuada, correcta o coherente — según el punto de vista de la Administración- lo que quiere.

Por ello, debemos considerar que la respuesta de la Administración no es sino una negativa encubierta, que siendo legítimo el argumento de la dificultad que esgrime, es a la misma a quien corresponde proponer soluciones a dicha dificultad y, por tanto, la conclusión ha de ser declarativa de la vulneración constitucional postulada. (STSJCV, de 7 de octubre de 2014, FD 3). ${ }^{53}$

Con posterioridad, y ahondando en esta perspectiva, el TSJCV ha manifestado que: «En orden a la afectación del funcionamiento del servicio como consecuencia de la facilitación de la documentación solicitada en el presente proceso, resulta anacrónico dicho argumento a la luz de las nuevas tecnologías que en la actualidad se dispone para proporcionar tal documentación» (STSJCV, 5. a, de 31 de octubre de 2016, recurso 212/2016, FD 3). Y también tiene interés el siguiente pronunciamiento al respecto (presente en otras dos resoluciones) del mismo órgano:

Dada la gran relevancia de los intereses en juego — derecho constitucional de participación en los asuntos públicos y de control de las instancias de poder- es indudable que las restricciones al ejercicio del mismo deben contener una explicación plena de las causas que impiden su ejercicio. Esta explicación no puede detenerse en la simple formulación del motivo que genera el rechazo. A la misma ha de adicionarse una amplia justificación de los hechos determinantes que lo solidifican.

Para lo que interesa en el proceso (...) tal justificación coincide con la prueba exacta del modo en que la concesión de los documentos pedidos (...) va a dañar el correcto funcionamiento de los servicios públicos que presta la Generalitat.

La prueba es más acuciante cuando la existencia de un necesario soporte informático de los informes de intervención anudado al racional y buen funcionamiento de los servicios públicos hace que la tenencia y obtención de dichos informes no parece que haya de ofrecer las dosis de dificultad y dedicación temporal a los que se remite el acuerdo (...). (STSJCV, 5. a, de 4 de noviembre de 2016, recurso 284/2016, FD 3; y la posterior STSJCV, 5. ${ }^{\text {, }}$, de 10 de enero de 2017, recurso 489/2016, FD 4)

En cuanto a la dispersión de la documentación, el TSJCV ha afirmado, con contundencia, que: «No es asumible, en absoluto, que un diputado autonómico haya de acudir a cada una de las Consellerías en las que se vertebra el funcionamiento de la Generalitat para lograr el acceso a la información que pide. Esa información se la ha de facilitar y entregar, sin duda, el propio conseller» (STSJCV, 5. ${ }^{\circ}$, de 4 de noviembre

53 Sobre este tema se ha vuelto a pronunciar expresamente la STSJCV, 5. ${ }^{\text {, }}$, de 10 de mayo de 2017, recurso 145/2016, reiterando los argumentos expuestos. 
de 2016, recurso 284/2016, FD 3; STSJCV, 5. , de 10 de enero de 2017, recurso 489/2016, FD 4; y STSJCV, 5. a , de 10 de mayo de 2017, recurso 145/2016, FD 4). $\mathrm{Al}$ respecto, se ha precisado, en este mismo sentido, que: "Teniendo en cuenta que esa información es plenamente accesible para la administración demandada y está en organismos dependientes de ella no resulta aceptable que se remita al diputado a los citados organismos para que la faciliten, debiendo ser la propia Conselleria la que lo haga» (STSJCV, 4. ${ }^{\mathrm{a}}$, de 20 de julio de 2017, recurso 132/2017, FD 3).

h) ¿Qué pasa cuando la documentación que se solicita es muy genérica?

Como ha podido verse supra — en el primero de los pasajes jurisprudenciales extractados en el apartado $g$ )_, este es un tema sobre el que la jurisdicción contencioso-administrativa también se ha pronunciado y, por ello, me remito aquí a lo transcrito en el citado apartado.

i) ¿Qué pasa cuando la documentación que se solicita implica a otras administraciones que gozan de autonomía propia?

Con relación a este tema, el TSJCV, ante un supuesto en el que se había denegado una solicitud de documentación que afectaba a las universidades públicas valencianas (en concreto, se solicitaba una relación detallada del número de cajas fijas existentes en ellas), consideró que, si bien era pertinente invocar — como la Generalitat había hecho- el principio de autonomía universitaria (derecho fundamental proclamado en el artículo 27.10 CE y en el artículo 79 de la LOU), no era menos cierto que su control o supervisión no escapa por completo a la administración autonómica, trayendo a colación para fundamentar la existencia de dicho vínculo una serie de normas ${ }^{54}$ (véase la STSJCV, 5. a , de 31 de octubre de 2016, recurso 212/2016).

A propósito de esta cuestión, posee indudable interés la interpretación en clave extensiva que realiza al respecto Montserrat Auzmendi del Solar — letrada del Parlamento Vasco- y que a continuación se transcribe en lo esencial:

Efectivamente, el derecho de los Parlamentos - lo que equivale a decir, de los parlamentarios - a obtener información, por medio del Gobierno, de las actividades de estos entes instrumentales no puede ser negado bajo el pretexto de la autonomía de que gozan dichas entidades o de la «privacidad» que caracterice a sus actuaciones o estructuras empresariales. Aunque sobre tales entidades el Gobierno no tenga, en sentido jurídico estricto, la «dirección», como sí la tiene sobre la Administración, no

${ }^{54}$ Ley 4/2007, de 9 de febrero, de Coordinación del Sistema Universitario Valenciano (art. 2.1); Ley Orgánica 6/2001, de 21 de diciembre, de Universidades (art. 79.2); Ley 1/2015, de 6 de febrero, de la Generalitat, de Hacienda Pública, del Sector Público Instrumental y de Subvenciones (art. 2.5); y Ley 2/2015, de 2 de abril, de la Generalitat, de Transparencia, Buen Gobierno y Participación Ciudadana de la Comunitat Valenciana. (arts. 1, 2 y 4). 
puede negarse que respecto de ellas el Gobierno tiene, desde luego, la «responsabilidad». Es por ello que el Gobierno está obligado a informar acerca de estos entes al Parlamento y a someterse en esta materia al control parlamentario. ${ }^{55}$

\section{SU GARANTÍA JURISDICCIONAL}

\subsection{Pluralidad de vías para la satisfacción de este derecho}

Si algo se ha expresado con nitidez en la jurisprudencia contencioso-administrativa de los últimos años es la idea de que el parlamentario que considere vulnerado su derecho a recabar documentación administrativa puede seguir el cauce previsto en el reglamento de la asamblea legislativa correspondiente para buscar así la satisfacción de su derecho o puede no hacerlo (es decir, no agotar la vía administrativo-reglamentaria) y acudir (entre otras posibles como, por ejemplo, la defensoría del pueblo) directamente a la vía jurisdiccional; en cuyo caso, podrá activarse — sin perjuicio de otros caminos procesales compatibles — el procedimiento preferente y sumario del art. 53.2 CE y los arts. 114 a 122 bis de la Ley 29/1998, de 13 de julio, reguladora de la jurisdicción Contencioso-administrativa.

En este sentido, el TSJCV ya apuntó tempranamente la idea de que «es constante la jurisprudencia que no exige en este tipo de procedimiento especial el agotamiento de la vía administrativa» (STSJCV, 5. a, de 29 de abril de 2011, recurso 659/2009, FD 2). Y, con posterioridad, el TS expresó sin ambages que: «Nada impide, desde luego, a los diputados que la hayan visto rechazada, en parte o en su totalidad, seguir el camino parlamentario previsto en el artículo 12 antes transcrito. Pero nada les impide tampoco hacer uso de los otros medios que el ordenamiento jurídico les brinda para defender su derecho fundamental y, en particular, de la tutela judicial» (STS, Sala de lo Contencioso, Sección 7. a, de 25 de febrero de 2013, recurso 4268/2011, FD 6). Este criterio ha sido posteriormente reiterado en la jurisprudencia tanto del propio TS como del TSJCV. Pero con todavía mayor claridad expositiva se expresó a este respecto el TS en sus resoluciones posteriores, que han terminado de asentar este criterio jurisprudencial:

Y, en cuanto a la posibilidad de que los diputados puedan optar entre seguir la vía ofrecida por el Reglamento de la cámara a la que pertenecen o pedir tutela judicial al derecho que le reconoce y que se integra en las atribuciones propias de su cargo público representativo, hay que recordar que son diversos los supuestos en que los interesados tienen varios caminos a su disposición para buscar la satisfacción de sus pretensiones sin que eso suponga quiebra de ningún principio o regla que deban ser observados. Basta con pensar en la posibilidad siempre existente de solicitar la intervención del Defensor del Pueblo o de acudir a vías

55 Auzmendi del Solar, M., op. cit., p. 270. 
diferentes de las judiciales para lograr el propósito que se desea. E, incluso, para obtener la tutela judicial hay casos en que son varios los caminos que se pueden emprender como, por ejemplo, sucede cuando cabe ensayar, incluso simultáneamente, el recurso especial para la protección de derechos fundamentales y el ordinario. (STS, Sala de lo Contencioso, Sección 7.a, de 15 de junio de 2015, recurso 3429/2013, FD 7; y STS, Sala de lo Contencioso, Sección 7.. a, de 15 de junio de 2015 , recurso 2165/2013, FD 8)

\subsection{Referencia a una polémica procesal de calado: ¿compete o no a la jurisdicción contencioso-administrativa enjuiciar actos del Gobierno que deniegan información a un representante politico?}

Pablo Lucas Murillo de la Cueva — magistrado del Tribunal Supremo, ponente de varias de las sentencias examinadas supra, y catedrático de derecho constitucional — ha incluido en su reciente trabajo sobre el particular ${ }^{56}$ una síntesis muy ilustrativa acerca de la evolución de la jurisprudencia y de la legislación en este punto. También Luis Latorre Vila realizó — hace aproximadamente un lustro- una brillante exégesis sobre la cuestión ${ }^{57}$. Así pues, a fin de no reiterar lo que en estos trabajos queda expuesto con formidable solvencia y claridad, bastará aquí con hacer mera referencia esquemática a los hitos más significativos que han jalonado el referido proceso evolutivo.

La primera cuestión que cabe señalar es que, en el marco regulatorio procesal anterior — esto es, el de la Ley, de 27 de diciembre de 1956, reguladora de la Jurisdicción Contencioso-administrativa- el TS interpretó que esta materia en concreto se situaba fuera del ámbito jurisdiccional contencioso-administrativo, puesto que se encuadraba de lleno en «el campo de los actos de gobierno o políticos sujetos a control parlamentario» (STS, Sala Quinta, Sección 1. a, de 9 de junio de 1987, recurso 708/1986, FD 3) o, si se prefiere, del «ámbito de las relaciones institucionales de los poderes políticos» (STS, Sala Quinta, Sección 1. a , de 15 de noviembre de 1988, recurso 1397/1988, FD 3). Y esta interpretación fue avalada por el TC, que consideró también que la materia en cuestión escapaba «de las que son objeto de control por la jurisdicción contencioso-administrativa» (STC 196/1990, FJ 5).

Poco tiempo después, cabe señalarlo, el propio TC abrió un cauce procesal para tutelar las potenciales lesiones al derecho de los representantes políticos a recabar documentación administrativa, al aceptar expresamente la vía del recurso de amparo constitucional como válida (STC 220/1991). En particular, el TC consideró adecuado — «forzando el tenor del artículo 43 LOTC», consideró posteriormente Javier García

56 Lucas Murillo de la Cueva, P., op. cit.

57 Latorre Vila, L. (2013). «La protección jurisdiccional del derecho de información de los parlamentarios. (A propósito de la «callada por respuesta»)». Cuadernos Manuel Giménez Abad, n. ${ }^{\circ} 5$, pp. 78-98.

(C) UNED. Revista de Derecho Politico 
$\operatorname{Roca}^{58}$ - que pudiera recurrirse a él de forma directa, precisamente, por no estar previsto procedimiento alguno ante la jurisdicción ordinaria (FFJJ 2 y 4$)^{59}$. Sin embargo, en este punto, Luis Latorre Vila ha negado que exista realmente amparo constitucional cuando se trata del derecho de los parlamentarios a recabar la información y documentación que obre en poder del Gobierno ${ }^{60}$.

$\mathrm{Al}$ margen de este hecho, con carácter posterior, se produjo un cambio decisivo en la jurisprudencia del TS que — en el marco de un proceso ajeno a la materia que aquí se estudia - pasó a afirmar su competencia para conocer y resolver recursos contra los actos de gobierno en todos aquellos de sus extremos regulados mediante «conceptos judicialmente asequibles» (STS, Pleno de la Sala Tercera, de 28 de junio de 1994, recurso 7105/1992, FD 1). Este criterio, que fue mantenido por el TS en resoluciones posteriores y hasta el día de hoy, tuvo, además, incidencia en el contenido de la posterior - y actualmente vigente- Ley 29/1998, de 13 de julio, reguladora de la Jurisdicción Contencioso-administrativa, que pasó a incluir una previsión en los siguientes términos:

Artículo 2.

El orden jurisdiccional contencioso-administrativo conocerá de las cuestiones que se susciten en relación con:

a) La protección jurisdiccional de los derechos fundamentales, los elementos reglados y la determinación de las indemnizaciones que fueran procedentes, todo ello en relación con los actos del Gobierno o de los Consejos de Gobierno de las Comunidades Autónomas, cualquiera que fuese la naturaleza de dichos actos.

Y estas son, en síntesis, las coordenadas generales que explican que, algunos años más tarde, y tras la judicialización de la materia en el ámbito de la Comunitat Valenciana - y del necesario conocimiento previo de tal conflictividad por parte del TSJCV_- el TS (STS, Sala de lo Contencioso, Sección 7. ., de 25 de febrero de 2013, recurso 4268/2011, y todas las posteriores) confirmase la competencia de la jurisdic-

58 García Roca, J., op. cit., p. 310.

59 Cuando, con anterioridad a esta sentencia, un grupo de diputados castellano-manchegos intentaron obtener el amparo constitucional por una (presunta) vulneración de este derecho perpetrada por el gobierno autonómico, el TC inadmitió el recurso alegando lo siguiente: "puede sostenerse que mientras los obstáculos al ejercicio de las facultades que integran la función parlamentaria provenientes de los propios órganos de las Cámaras si son, en principio, susceptibles de revisión en amparo, las respuestas o actuaciones del Ejecutivo en réplica a tal ejercicio constituyen, también en principio, el ejercicio de las propias funciones gubernamentales, susceptibles de control político y parlamentario - y, en última instancia, electoral-, pero no revisables en general desde consideraciones de corrección jurídica, so riesgo de pretender una judicialización inaceptable de la vida política, no exigida, en modo alguno, por la Constitución» (ATC 426/1990, FJ 3). Y es que, en efecto, la jurisprudencia constitucional anterior relativa a este mismo derecho (es decir, las SSTC 161/1988 y 181/1989 ya examinadas supra) traían causa de la impugnación de acuerdos de las Mesas de las asambleas legislativas autonómicas implicadas en cada caso y no de las respuestas ofrecidas por los gobiernos respectivos.

${ }^{60}$ Latorre Vila, L., op. cit., pp. 87-89. 
ción contencioso-administrativa para conocer de este tipo de controversias gobierno-parlamento ${ }^{61}$.

\subsection{Consideraciones adicionales sobre la «efectividad»y la «idoneidad» de la garantía jurisdiccional de este derecho}

Al hilo de lo anterior no puede dejar de señalarse que, como certeramente ha observado Fernando Santaolalla López, las resoluciones adoptadas por el TC sobre esta materia en años anteriores no pasaron de quedarse «en una condena puramente retórica», ya que para haber tenido el deseado efecto reparador deberían haberse dictado «en tiempo suficiente para remediar el mal causado» pues, de lo contrario, «su intervención se hace inútil» ${ }^{62}$. Y es que, como sucede con la tutela de cualquier otro derecho perteneciente al ámbito representativo, de poco o nada sirve una sentencia dictada cuando la legislatura ha concluido y, en consecuencia, los poderes implicados en la controversia se han disuelto y han vuelto a constituirse ex novo.

Pues bien, el hecho de que la jurisdicción contencioso-administrativa se haya declarado competente en los últimos años para conocer de esta clase de controversias ha comportado, sin duda, una mejora sustancial con relación al escenario anterior. En este sentido, Pablo Lucas Murillo de la Cueva ha expresado con nitidez que «el control judicial de estos actos del Gobierno sí puede significar una respuesta más ágil que la que está en condiciones de dar el Tribunal Constitucional» ${ }^{63}$.

Pero, al margen del debate acerca de cuál es (o debería ser) la jurisdicción competente en este tipo de asuntos, tiene sentido plantearse si acaso no cabría concebir un cauce procesal alternativo a los procedimientos judiciales indicados supra para solventar las controversias suscitadas en torno a las solicitudes parlamentarias de documentación administrativa. El tema abre no pocas incógnitas, pero tal vez cabría retomar la idea del conflicto entre órganos constitucionales a instancia de las minorías parlamentarias, apuntado en su día por Javier García Roca, y reavivar de este modo un debate cuyo sentido no debe ser otro que el de encontrar soluciones viables que ponderen de la forma más equilibrada los distintos intereses en liza:

Estamos ante un supuesto de hecho que estimo claramente configura lo que en la Teoría de la Constitución, no así en nuestro Derecho Constitucional, un conflicto entre órganos constitucionales, referido a la respectiva esfera de atribuciones del ejecuti-

${ }^{61}$ Obsérvese que en el caso de la STC 32/2017, esto es, el recurso del Grupo Parlamentario Popular de las Cortes de Castilla-La Mancha contra un acuerdo de su Mesa en virtud del cual se inadmitieron a trámite determinadas solicitudes de información al gobierno autonómico, hubo un primer intento de acudir a la jurisdicción contencioso-administrativa que no prosperó por declararse ésta incompetente (véase el ATSJCLM, 2. ${ }^{a}$, de 22 de octubre de 2015). Sin embargo, en este supuesto, no se dirimía una negativa proveniente del gobierno, sino de la propia asamblea legislativa, motivo que explica que no tuviese recorrido procesal en el orden contencioso-administrativo.

62 Santaolalla López, F., op. cit., p. 127.

63 Lucas Murillo de la Cueva, P., op. cit., p. 195. 
vo y del legislativo. En este proceso puede perfectamente dilucidarse la intensidad de la obligación del Gobierno de contestar al Parlamento, especialmente, cuando estén en juego otros bienes constitucionales como, $v$. gr., pueden ser el interés de la defensa y seguridad nacionales o el alcance de los secretos oficiales. Así se regula procesalmente en otros ordenamientos, atribuyendo su resolución al Tribunal Constitucional como garante de la separación horizontal de poderes.

La inexistencia en nuestro Derecho de un conflicto entre órganos constitucionales a instancias de esas fracciones de órganos que son las minorías parlamentarias, por su ausencia de regulación en la Ley Orgánica, supone un déficit de protección constitucional de nuestro ordenamiento, como ya denuncié en 1987 y sigue sin remediarse. ${ }^{64}$

A este respecto Martín María Razquin Lizárraga — quien también ha manifestado su preocupación por la ineficacia que supone obtener sentencias con retraso- ha considerado, en el marco de su reciente propuesta de acudir (de forma supletoria) a la legislación de transparencia ante supuestos de este tipo, que «debería abrirse la posibilidad de que los diputados pudieran presentar reclamaciones ante las autoridades de transparencia contra la negativa a darles información solicitada»; agregando que «la incorporación de esta posibilidad debe ser expresa y puede ser efectuada bien por los reglamentos o por las leyes reguladoras del derecho de acceso» ${ }^{65}$. Sobre la competencia de las autoridades de transparencia para conocer de las reclamaciones interpuestas por representantes políticos (en su condición de tales) ha reflexionado también Emilio Guichot Reina ${ }^{66}$.

\section{UN APUNTE FINAL SOBRE EL (POTENCIAL) EJERCICIO ABUSIVO DE ESTE DERECHO}

Antes de concluir parece conveniente adicionar alguna reflexión en torno a un tema que ha venido debatiéndose durante los últimos tiempos y que reviste indudable interés: el posible ejercicio espurio de este derecho, es decir, la perspectiva de que pueda ser utilizado, no para cumplir con la tarea fiscalizadora del gobierno que corresponde desempeñar al representante, sino para obstruir el normal funcionamiento de aquél o incluso para desgastarlo políticamente. Se trata de un debate real —no inédito en otras latitudes — que ha surgido dentro del ámbito de la Comunitat Valenciana a raíz de la alternancia en el ejecutivo autonómico producida en el año 2015 (y en virtud de la cual, como resulta obvio, quienes antes eran gobierno ahora son oposición parlamentaria $)^{67}$. Una circunstancia - ya de por sí preocupan-

\footnotetext{
${ }^{64}$ García Roca, J., op. cit., pp. 307-311.

65 Razquin Lizárraga, M. M., op. cit., pp. 67-68.

66 Guichot Reina, E., op. cit., pp. 44-47.

${ }^{67}$ Una reciente STSJCV ha dicho a este respecto que: «Debemos destacar que el hecho de que el solicitante perteneciera al Partido gobernante en los años cuya información se solicita, e incluso que
} 
te si se valoran sus potenciales consecuencias- que, paradójicamente, puede verse agravada por la existencia de un corpus jurisprudencial como el examinado toda vez que ha dotado de un plus de legitimidad a los representantes políticos en sus demandas de información que, como acaba de indicarse, en los últimos tiempos parecen inscribirse más en la lógica de la contienda partidista que busca erosionar la gestión del adversario político que en la genuina (y necesaria) función parlamentaria de control al gobierno.

Pues bien, al margen de valoraciones de naturaleza política — que no corresponde realizar aquí - resulta pertinente efectuar un apunte al respecto desde una óptica meramente jurídica. Y es que, en previsión de impedir «ciertas prácticas abusivas u obstruccionistas del buen funcionamiento de la Administración», el ya citado Javier García Roca propuso - hace ya casi dos décadas- conferir determinadas potestades a los órganos de gobierno de las asambleas legislativas a tal efecto ${ }^{68}$; como también, por su parte, Fernando Sáinz Moreno planteó una serie de razonables - criterios que eventualmente pudiesen limitar, desde esta perspectiva, las facultades parlamentarias de recabar información ${ }^{69}$; o como Juan José Lavilla Rubira $^{70}$ o Monteserrat Auzmendi del Solar ${ }^{71}$, entre otros, han reclamado el cumplimiento del requisito de la conexión entre lo solicitado y el cumplimiento de las funciones parlamentarias del solicitante ${ }^{72}$. Por su parte, Martin María Razquin Lizárraga ha propuesto acudir — de forma supletoria- a los límites previstos en la legislación de transparencia ${ }^{73}$. Se trata, en todos los casos, de propuestas que abogan por la aplicación de criterios de ponderación que permitan cohonestar el normal ejercicio de este derecho fundamental con la existencia de límites que impidan eventuales utilizaciones desviadas del mismo. Pues bien, ante el advenimiento de escenarios otrora meramente hipotéticos pero ya constatados en la práctica, urge que reflexionemos en torno a tales cuestiones y profundicemos en este debate a fin de hallar soluciones que eviten la normalización de esta clase de actuaciones por parte de nuestros representantes políticos.

tuviera cargo alguno en el Gobierno de la Generalidad, no responde sino a la alternancia en el mismo, propia de nuestro sistema constitucional, que no merma en absoluto sus derechos actuales como Diputado de la oposición, por lo que se trata de una cuestión irrelevante en autos» (STSJCV, 5. ${ }^{a}$, de 10 de mayo de 2017, recurso 145/2016, FD 4).

68 García Roca, J., op. cit., pp. 305-306.

69 Sáinz Moreno, F., op. cit., pp. 81-115.

${ }^{70}$ Lavilla Rubira, J. J. (1991). «Congreso de los Diputados y demás poderes públicos: información, control y responsabilidad», en Martín-Retortillo Baquer, S., (coord.), Estudios sobre la Constitución Española: Homenaje al profesor Eduardo García de Enterría, vol. 3, Madrid, Civitas, p. 2018.

${ }^{71}$ Auzmendi del Solar, M., op. cit., p. 273.

72 Recuérdese que la STC 32/2017 ha afirmado que la Mesa puede fundamentar su decisión de calificación y admisión a trámite «en la existencia de una conexión o no de los documentos requeridos con dicha función de control» (FJ 6 in fine).

73 Razquin Lizárraga, M. M., op. cit., pp. 37-69. 


\section{ANEXO JURISPRUDENCIAL}

\section{JURISPRUDENCIA DEL TRIBUNAL CONSTITUCIONAL}

(Específica sobre el derecho de los representantes políticos a recabar documentación administrativa) STC 161/1988, de 20 de septiembre STC 181/1989, de 3 de noviembre STC 196/1990, de 29 de noviembre ATC 426/1990, de 11 de diciembre STC 220/1991, de 25 de noviembre STC 203/2001, de 15 de octubre STC 57/2011, de 3 de mayo STC $32 / 2017$, de 27 de febrero

\section{JURISPRUDENCIA DEL TRIBUNAL SUPREMO}

STS, Sala de lo Contencioso, Sección 7. a, de 25 de febrero de 2013, recurso 4268/2011 STS, Sala de lo Contencioso, Sección 7. a, de 1 de junio de 2015, recurso 956/2014 STS, Sala de lo Contencioso, Sección 7. a, de 15 de junio de 2015, recurso 3429/2013 STS, Sala de lo Contencioso, Sección 7.a, de 15 de junio de 2015, recurso 2165/2013

\section{JURISPRUDENCIA DEL TRIBUNAL SUPERIOR DE JUSTICIA DE LA COMUNITAT VALENCIANA}

STSJCV, 5. ${ }^{\text {, }}$, de 29 de abril de 2011, recurso 659/2009

STSJCV, 5. ${ }^{a}$, de 19 de junio de 2013, recurso 30/2012

STSJCV, 5. ${ }^{a}$, de 14 de enero de 2014, recurso 58/2013

STSJCV, 5. ${ }^{a}$, de 27 de marzo de 2014, recurso 197/2013

STSJCV, 5. ${ }^{a}$, de 18 de febrero de 2014, recurso 139/2013

STSJCV, 5. ${ }^{a}$, de 18 de febrero de 2014, recurso $120 / 2013$

STSJCV, 5. ${ }^{a}$, de 26 de febrero de 2014, recurso 298/2013

STSJCV, 5. ${ }^{\text {a }}$ de 5 de marzo de 2014, recurso 319/2013

STSJCV , 5. ${ }^{a}$, de 11 de marzo de 2014, recurso 142/2013

STSJCV, 5. a, de 2 de abril de 2014, recurso 297/2013

STSJCV, 5. ${ }^{\mathrm{a}}$, de 9 de abril de 2014, recurso 427/2013

STSJCV, 5.a , de 13 de mayo de 2014, recurso 389/2013

STSJCV , 5. ${ }^{a}$, de 20 de mayo de 2014, recurso 483/2013

STSJCV, 5. ${ }^{a}$, de 20 de mayo de 2014, recurso 449/2013

STSJCV, 5. ${ }^{a}$, de 30 de mayo de 2014, recurso 548/2013 
STSJCV, 5. ${ }^{\mathrm{a}}$, de 4 de junio de 2014, recurso 507/2013

STSJCV, 5. ${ }^{a}$, de 10 de junio de 2014, recurso 549/2013

STSJCV, 5. ${ }^{a}$, de 10 de junio de 2014, recurso 542/2013

STSJCV, 5. ${ }^{a}$, de 11 de junio de 2014, recurso 547/2013

STSJCV, 5. ${ }^{a}$, de 27 de junio de 2014, recurso 482/2013

STSJCV, 5. ${ }^{a}$, de 30 de junio de 2014, recurso 543/2013

STSJCV , 5. a, de 24 de septiembre de 2014, recurso 116/2014

STSJCV, 5. a, de 29 de septiembre de 2014, recurso 546/2013

STSJCV, 5. ${ }^{a}$, de 7 de octubre de 2014, recurso 350/2013

STSJCV, 5. ${ }^{a}$, de 7 de octubre de 2014, recurso 545/2013

STSJCV, 5. ${ }^{a}$, de 28 de octubre de 2014, recurso 117/2014

STSJCV, 5. ${ }^{\text {, }}$, de 29 de octubre de 2014, recurso 95/2014

STSJCV, $5 .{ }^{a}$, de 5 de noviembre de 2014, recurso 175/2014

STSJCV, 5. ${ }^{a}$, de 12 de noviembre de 2014, recurso 210/2014

STSJCV, 5. ${ }^{a}$, de 17 de diciembre de 2014, recurso 187/2014

STSJCV, 5. ${ }^{a}$, de 21 de enero de 2015, recurso 657/2014

STSJCV, 5. . , de 25 de marzo de 2015, recurso 418/2013

STSJCV, 5. ${ }^{a}$, de 14 de julio de 2015, recurso 989/2014

STSJCV, 5. ${ }^{a}$, de 20 de septiembre de 2016, recurso 792/2015

STSJCV, 5. ${ }^{\text {, }}$, de 31 de octubre de 2016, recurso 212/2016

STSJCV, 5. ${ }^{a}$, de 4 de noviembre de 2016, recurso 284/2016

STSJCV, 5. ${ }^{a}$, de 10 de enero de 2017, recurso 489/2016

STSJCV, 5. a, de 28 de febrero de 2017, recurso 161/2016

STSJCV, 5. ${ }^{a}$, de 10 de mayo de 2017, recurso 145/2016

STSJCV, 4. ${ }^{a}$, de 20 de julio de 2017, recurso 132/2017

STSJCV , 5. ${ }^{a}$, de 15 de septiembre de 2017 , recurso 972/2016

STSJCV, 5. ${ }^{a}$, de 20 de septiembre de 2017, recurso 815/2016 
Title:

The right of parliamentarians to obtain administrative documentation. New jurisprudential perspectives as a result of its increasing judicialization.

\title{
Summary:
}

1. Introduction. 2. The jurisprudential interpretation of this right: Recent applications (and modulations) by the jurisdiction contentious-administrative doctrinal criteria consolidated in the jurisprudence of the Constitutional Court. 2.1. Typology and defining elements of this right. 2.2. Potentially conflicting situations derived of the exercise of this right. 3. Its jurisdictional guarantee. 3.1. Plurality of ways to satisfy this right. 3.2. Reference to a controversial procedural issue: Is the contentious-administrative jurisdiction competent to judge this type of government acts? 3.3. Additional considerations on «effectiveness» and «suitability» of the jurisdictional guarantee of this right. 4 . A final note about the (potential) abusive exercise of this right. 5. Jurisprudential Annex.

\section{Resumen:}

Desde hace poco más de un lustro, por vez primera en nuestra historia democrática, el derecho de los parlamentarios a recabar documentación de las administraciones públicas se ha judicializado en la vía contencioso-administrativa. Un cúmulo de casos con un único foco común: las tensas relaciones gobierno-parlamento en el ámbito de la Comunitat Valenciana. Dicha conflictividad ha dado lugar, en el transcurso de estos años, a un elevado número de resoluciones tanto del Tribunal Superior de Justicia de la Comunitat Valenciana como del Tribunal Supremo. Un total de más de cuarenta sentencias que han incidido de forma considerable en la delimitación de este derecho. El presente artículo examina dichas resoluciones judiciales y ofrece un análisis global de los criterios interpretativos contenidos en las mismas. Una tarea de exégesis que se ha realizado sin perder de vista la jurisprudencia dictada por el Tribunal Constitucional acerca de esta misma cuestión.

\begin{abstract}
:
For just over five years, for the first time in our democratic history, the right of parliamentarians to collect documentation from public administrations has been judicialized in the contentious-administrative way. A cluster of cases with a single common focus: tense government-parliament relations in the Valencian Community. This conflict has led, in the course of these years, to a high number of resolutions of both the Superior Court of Justice of the Valencian Community and the Supreme Court. A total of more than forty sentences that have had a considerable impact on the delimitation of this right. This article examines these judicial resolutions
\end{abstract}


and offers a global analysis of the interpretive criteria contained in them. A task of exegesis that has been carried out without losing sight of the jurisprudence dictated by the Constitutional Court on this same issue.

Palabras clave:

Parlamentarismo multinivel; control parlamentario; ius in officium; transparencia; relaciones gobierno-parlamento.

Key words:

Multilevel parliamentarism; parliamentary control; ius in officium; transparency; government-parliament relations. 